\title{
A comprehensive review of the polymer-based hydrogels with electrochemically synthesized silver nanoparticles for wound dressing applications
}

\author{
Katarina Nešović | Vesna Mišković-Stanković $\mathbb{~}$
}

Faculty of Technology and Metallurgy, University of Belgrade, Belgrade, Serbia

\section{Correspondence}

Vesna Mišković-Stanković, Faculty of Technology and Metallurgy, University of Belgrade, Karnegijeva 4, Belgrade, Serbia.

Email: vesna@tmf.bg.ac.rs

\section{Funding information}

Ministarstvo Prosvete, Nauke i

Tehnološkog Razvoja, Grant/Award

Numbers: 451-03-68/2020-14/200135,

451-03-68/2020-14/200287

\begin{abstract}
Modernization and improvement of wound dressing materials is an important topic in biomaterials and biomedicine fields, as the traditional materials are inadequate and susceptible to bacterial infections. In recent times, polymerbased hydrogel materials have presented themselves as excellent candidates for new-generation wound dressings with improved properties, such as high sorption ability, good mechanical properties, and low adhesiveness. Additionally, cross linked hydrogel matrices serve as excellent carriers for controlled release of antibacterial agents, such as silver nanoparticles (AgNPs), which are preferred over conventional antibiotics due to multi-phase mechanism of action and low susceptibility to induce bacterial resistance. Their incorporation inside polymer matrices allows improvement of wound dressing properties and sustained protection against bacterial infection. Electrochemical methods for AgNPs synthesis are facile and green alternatives to chemical routes, allowing the formation of highly stable AgNPs with strong antibacterial effect. In this article, we aim to provide a comprehensive review of the existing research on the topic of electrochemically synthesized silver nanoparticles incorporated in polymer matrices with a special focus on the chitosan-based hydrogels as prospective materials for wound dressing applications.
\end{abstract}

\section{KE Y W O R D S}

chitosan, electrochemical reduction, hydrogels, silver nanoparticles, silver release, wound dressings

\section{1 | INTRODUCTION}

Recent developments in biomaterials science have seen increasing interest in (re)search for novel solutions for new-generation wound dressing materials. Commonlyused dressings and bandages are able to only provide a physical protection of the wound during the healing process and as such they have many drawbacks. ${ }^{1}$ For one, although sterile initially, they are very prone to bacterial infection and therefore carry with their usage inherent risks for patients, especially during chronic wound treatment. Further, the usual dressings are mostly cotton-based materials which tend to dry out quickly and provide poor moisture regulation, which is crucial for wound healing. This also carries along another shortcoming, which is sticking to the wound tissue and damage upon replacement. The proneness to bacterial infection, on the other hand, dictates the need to frequently change these dressings, which could enhance the risk of wound tissue damage and thus could impede normal healing process. On a 
related note, the susceptibility to bacterial adhesion mandates the local/topical applications of drugs, usually antibiotics, to prevent infection. The widespread use of antibiotics has led to resistance developing in many bacterial strains, which has become a very common and a very serious problem. ${ }^{2}$ Thus, a vicious circle emerges, carrying along grave and almost fatal consequences.

In an effort to alleviate the inherent risks connected to traditional wound dressings, novel materials have emerged, and have been the focus of many researchers around the world during the last couple of decades. These new materials are predominantly biopolymer-based hydrogels and films, and have been shown to possess significantly improved properties-superior gas/water vapor permeability, low adhesiveness, good swelling, absorption and moisture regulation properties, and biocompatibility. ${ }^{3}$ The choice of polymer components is almost an "embarrassment of riches," with many viable options presented in the existing body of research. The most "popular" wound dressing polymers are natural-origin ones such as alginate, ${ }^{4,5}$ cellulose, ${ }^{6}$ chitin and chitosan, ${ }^{7}$ but also synthetic biopolymers including poly(vinyl alcohol $)^{8,9}$ and poly(vinyl pyrrolidone). ${ }^{10,11}$ Frequent focus of wound dressing materials studies is also on blends, copolymers, and grafts of aforementioned polymers, ${ }^{12,13}$ as well as their chemically modified derivatives. ${ }^{14,15}$

Along with improved physical properties of the dressing, the aim is to incorporate an antibacterial agent in order to achieve active protection from bacterial infection. In this sense, recent research has seen a significant shift away from antibiotics and toward other active components which would provide similar or better antibacterial activity without the risk of bacterial resistance. Among the most common alternative antibacterial agents are metal and especially silver nanoparticles (AgNPs) due to their widespectrum activity and low susceptibility for bacterial resistance. ${ }^{16}$ Indeed, the mechanistic aspects of AgNPs antibacterial action have been widely explored but not yet conclusively determined, as they include "attack on several fronts"-cytoplasmic membrane damage, disruption of DNA replication through binding to sulfur- and phosphorus-containing groups, inhibition of respiratory processes, as well as reactive oxygen species (ROS) generation, causing membrane and protein damage. ${ }^{16-18}$ Due to their very potent and diverse antibacterial activity, AgNPs have become a popular choice of antibacterial component in polymer-based wound dressings. ${ }^{19}$

If one choses to incorporate AgNPs inside a wound dressing hydrogel, for example, there are various possibilities for their synthesis and immobilization, which offer different methods of obtaining AgNPs, along with tuning their sizes and size distributions, shapes, and morphologies. Silver nanoparticle-incorporated hydrogels could be obtained by in situ AgNPs synthesis, or by synthesizing AgNPs first and then incorporating them in the polymer matrix. The synthesis itself is most commonly achieved via reduction from an ionic $\mathrm{Ag}^{+}$precursor, usually silver nitrate solution. Most frequently applied methods in the literature are chemical reduction (with a strong reducing agent such as $\left.\mathrm{NaBH}_{4}\right),{ }^{20}$ or $\gamma$-irradiation technique, which enables reduction of silver ions to $\mathrm{Ag}^{\mathrm{O}}$ with free radicals. ${ }^{10,21-23}$ Both of these methods have their advantages, but both also have their drawbacks. The chemical reduction method is attractive because it is relatively easy to perform, enables high yield of the synthesis and facilitates the control of AgNPs size and homogeneous distribution. ${ }^{24}$ On the other hand, the use of potentially toxic chemical agents could compromise biocompatibility of the material and special care must be taken to wash out and extract leftover chemicals. ${ }^{3,25}$ Gamma irradiation is a greener method which helps avoid potential chemical toxicity allowing simultaneous cross linking and sterilization of hydrogel. ${ }^{3}$

Recently, there has been an increasing interest in electrochemical routes for AgNPs synthesis, as this method provides both green reduction without the use of chemicals (apart from ionic precursor), as well as the inexpensive equipment which is accessible and easy to handle. AgNPs could be electrochemically synthesized galvanostatically or at constant voltage, in or ex situ, in colloid solutions of polymers ${ }^{26-29}$ or directly inside the hydrogel. ${ }^{30-36}$

In this article, we aim to present an overview of the recent progress in electrochemical methods of AgNPs incorporation in polymer-based materials for wound dressing applications, with a special focus on chitosan as a prospective material. To our knowledge, there is no such review in the current state-of-the-art literature and it is important to cover the green electrochemical alternatives for the facile and clean production of AgNPs with tailored properties for wound dressing applications. The properties and specificities of biopolymer wound dressing materials in different forms will be reviewed in the following chapters; further, the mechanistic and technical aspects of the electrochemical synthesis will be outlined; a comparison will be drawn among different methods and materials, and finally, the future prospects and outlook will be presented on the basis of recent developments in this branch of science.

\section{I POLYMER HYDROGELS AND FILMS FOR WOUND DRESSING APPLICATIONS}

As already mentioned, a major focus of research in biomaterials field is finding new materials for wound 
dressings which would have improved properties and circumvent inherent shortcomings of traditional wound dressings, gauzes and bandages. These new materials need to possess a number of properties which correspond to the requirements of wound care. Some of these properties $\operatorname{are}^{37-40}$ : (a) biocompatibility and nontoxicity toward healthy tissue, (b) good wound exudate absorption ability, (c) good gas permeability $\left(\mathrm{O}_{2}, \mathrm{CO}_{2}\right.$, water vapor), (d) the ability to maintain moist wound environment and to prevent the drying of the wound, (e) sterility and barrier properties against microorganisms, (f) the ability to maintain optimal wound temperature, and (g) low adhesiveness to the wound tissue, and so on.

Next-generation biomaterials, especially biopolymerbased hydrogels have for quite some time been at the forefront of wound dressing research., $37,38,40-42$ This is hardly surprising because of their exceptional tailorability and the ability to address some or all of the issues listed above., ${ }^{3,37}$ A wide array of polymers has been used for active wound dressing applications, both synthetic and natural-origin. The polymers derived from natural resources include various polysaccharides such as cellulose, ${ }^{43,44}$ starch, ${ }^{45}$ dextran, ${ }^{46,47}$ chitosan, ${ }^{48-50}$ alginates, ${ }^{51,52}$ hyaluronic acid, ${ }^{53-55}$ but also some protein-based biopolymers including keratin ${ }^{56}$ and collagen, ${ }^{50,53,55}$ gelatin, ${ }^{57,58}$ silk fibroin and sericin. ${ }^{59}$ On the other hand, bioactive or bioinert synthetic polymers used in wound dressing research encompass some hydrophobic materials such as polycaprolactone, ${ }^{60}$ polypropylene, ${ }^{61}$ and poly(lactic acid), ${ }^{62-64}$ and different hydrophilic synthetic polymers, for example, poly(vinyl alcohol), ${ }^{65-67}$ poly(methacrylic acid) ${ }^{68}$ and poly(ethylene glycol). ${ }^{60,69}$ Both natural-origin and synthetic polymers are also rarely used "stand-alone" to produce wound dressing materials, as blending, grafting and copolymerization opens a much wider spectrum of structures and properties and provides the pathway to controlled production of tailor-made materials. This is why the wound dressings are usually made from blends or copolymers of above mentioned polymers. The choice of antibacterial agent, however, also to some degree dictates the choice of polymer components, and especially in the case of silver nanoparticles it is important to carefully chose the polymers which would exert excellent stabilization effect, while at the same time providing sustained, and preferably controllable release of AgNPs into the wound area to achieve maximum protection against bacterial and other infections.

Chitosan (CHI) is especially interesting as the only natural polycationic polysaccharide and a biopolymer with intrinsic antibacterial properties that make it an excellent choice for wound dressing applications. A polysaccharide of natural origin, it is usually obtained by partial or complete deacetylation of chitin. ${ }^{70}$ It has gained considerable attention in biomaterials research, including wound dressings and drug delivery, ${ }^{71-73}$ due to its remarkable properties, such as intrinsic antibacterial activity, biocompatibility, and biodegradability. ${ }^{70}$ As a result of partial chitin deacetylation, $\mathrm{CHI}$ contains many amino $\left(-\mathrm{NH}_{2}\right)$ groups on its chain, which are subject to protonation in acidic media, gaining positive charge and becoming $-\mathrm{NH}_{3}{ }^{+} \cdot{ }^{70}$ Thus, $\mathrm{CHI}$ is soluble in acidic, but not in alkaline media, and its pH-dependent solubility has been used to tailor the properties of biomaterials. Another consequence of $\mathrm{pH}$-dependent solubility is the fact that CHI is the only natural polycation, which enables formation of polyelectrolyte complexes with other polymers, such as alginate. Some studies have argued that precisely the presence of $-\mathrm{NH}_{3}{ }^{+}$on chitosan chain is the reason of its antibacterial properties, as they allow interactions with negatively charged bacterial cytoplasmic membranes, disrupting their functions and interfering with respiratory and other processes, which leads to cell death. ${ }^{70,74-79}$ Chitosan has also been shown to possess the ability to promote wound healing. ${ }^{75,80}$

Due to presence of polar $-\mathrm{OH}$ and $-\mathrm{NH}_{2}$ groups, chitosan has been identified as an efficient stabilizing agent for metallic nanoparticles, and many research works were dedicated to obtaining chitosan-based biomaterials containing AgNPs. ${ }^{12,81-83}$ What is more, $\mathrm{CHI}$ is also a mild reducing agent, thus enabling green synthesis of AgNPs without other chemical reducents. ${ }^{84}$ However, one drawback of pure chitosan hydrogels is the fact that they have poor mechanical properties, especially those prepared by physical cross linking methods. ${ }^{70}$ For this reason, chitosan is rarely used in pure form, rather it is utilized to form blends with other polymers, such as alginate or PVA. ${ }^{85,86}$ $\mathrm{PVA} / \mathrm{CHI}$ blends are especially interesting as the presence of PVA facilitates physical hydrogel formation through freezing-thawing and provides structural integrity to the matrix, whereas chitosan improves antibacterial properties and enables better immobilization of AgNPs inside the hydrogel. ${ }^{34}$ However, of course, chitosan has been successfully utilized in combination with other polymer materials to prepare wound dressings with improved properties. Table 1 represents an overview of some chitosan-based wound dressing systems incorporating silver nanoparticles as an antimicrobial agent. One thing that particularly stands out from the data presented in Table 1 is certainly the vast versatility of chitosan as a wound dressing material. The production of the hydrogel can be achieved via different methods, and chitosan is most frequently applied as a blend, or a copolymer with different polymeric materials, such as gelatin, ${ }^{87-89}$ dextran,,$^{90}$ alginate, ${ }^{91,92}$ hyaluronic acid, ${ }^{93}$ polyacrylamide, ${ }^{94}$ or $\mathrm{PVA}^{36,95,96}$; however, some studies report free-standing AgNP-containing pure chitosan hydrogels. ${ }^{97-100}$ The versatility of possible 
T A B L E 1 Overview of some recent chitosan-based wound dressing hydrogels with AgNPs, with comparisons of the different synthesis methods, antibacterial, and other biological properties

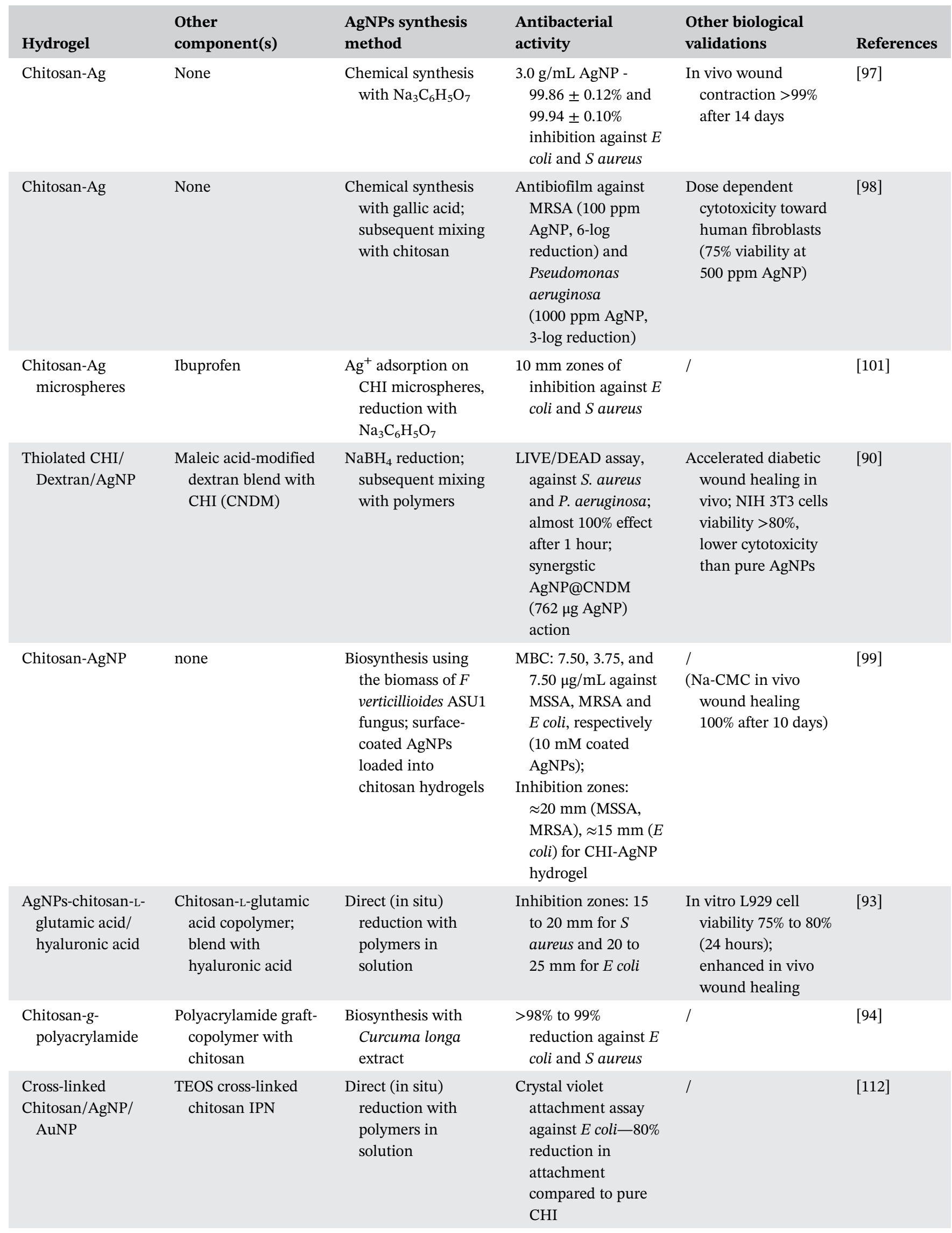


T A B L E 1 (Continued)

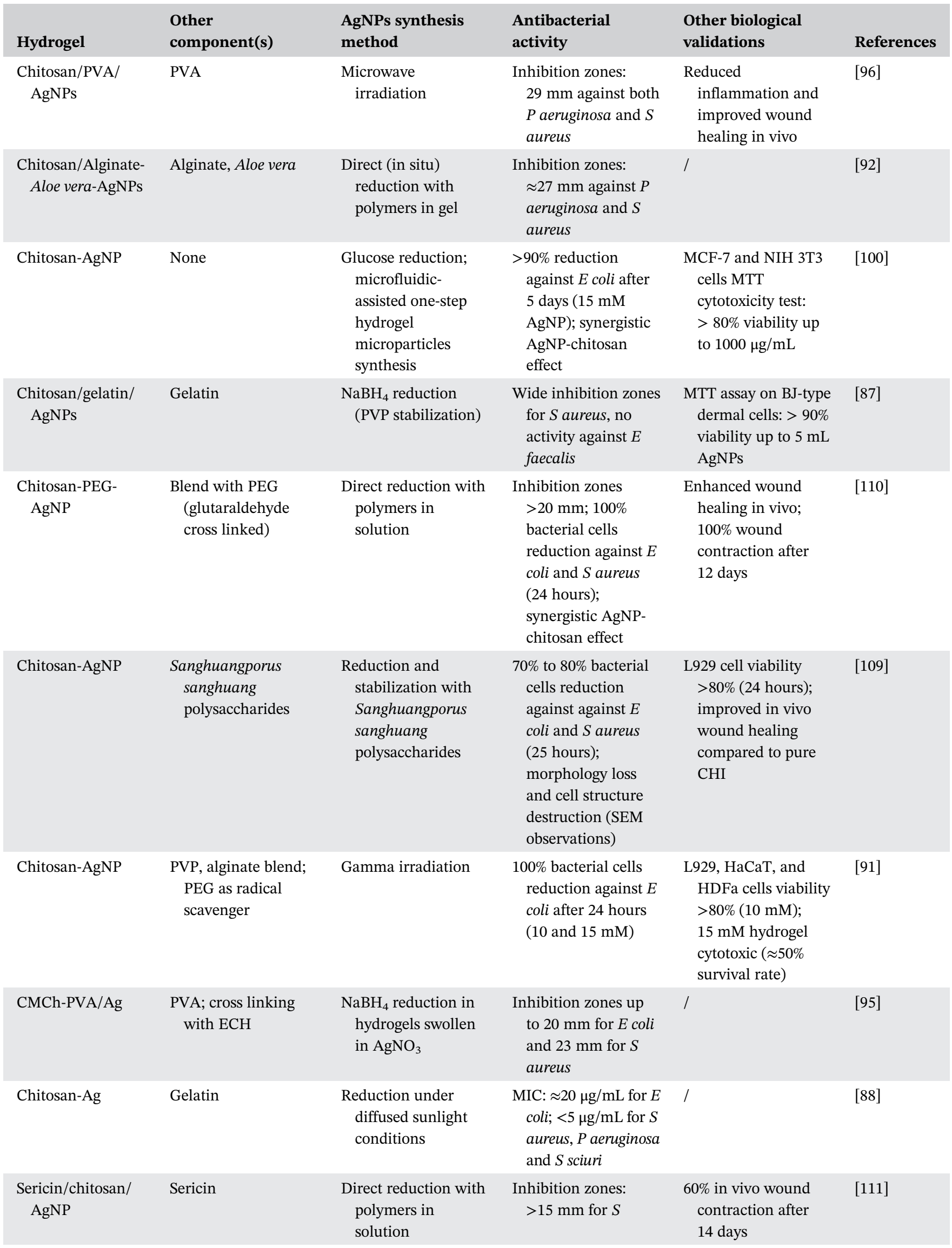


T A B LE 1 (Continued)

\begin{tabular}{|c|c|c|c|c|c|}
\hline Hydrogel & $\begin{array}{l}\text { Other } \\
\text { component(s) }\end{array}$ & $\begin{array}{l}\text { AgNPs synthesis } \\
\text { method }\end{array}$ & $\begin{array}{l}\text { Antibacterial } \\
\text { activity }\end{array}$ & $\begin{array}{l}\text { Other biological } \\
\text { validations }\end{array}$ & References \\
\hline & & & $\begin{array}{l}\text { aureus and } \\
>20 \mathrm{~mm} \text { for } E \text { coli }\end{array}$ & & \\
\hline Ag/PVA/CHI & $\begin{array}{l}\text { PVA; different CHI } \\
\text { contents }\end{array}$ & $\begin{array}{l}\text { Electrochemical } \\
\text { synthesis (in situ) }\end{array}$ & $\begin{array}{l}100 \% \text { bacterial cells } \\
\text { reduction against } E \\
\text { coli and } S \text { aureus } \\
\text { after } 60 \text { minutes } \\
(0.25 \mathrm{mM} \mathrm{Ag);} \\
\text { synergistic AgNP- } \\
\text { chitosan effect }\end{array}$ & $\begin{array}{l}\text { MTT assay: L929, } \\
\text { MRC-5 viability } \\
\text { >90\% to } 100 \%(0.25 \\
\text { and } 3.9 \mathrm{mM} \mathrm{Ag,} \\
48 \text { hours })\end{array}$ & {$[36]$} \\
\hline
\end{tabular}

Abbreviations: $\operatorname{AgNP}(\mathrm{s})$, silver nanoparticles; CHI, chitosan; ECH, epichlorohydrin (cross linking agent); L929, mice fibroblast cell line; MCF-7, breast cancer cell line; MRSA, methicillin-resistant Staphylococcus aureus; MSSA, methicillin-susceptible Staphylococcus aureus; MTT, 3-(4,5-dimethylthiazol-2-yl)-2,5-diphenyltetrazolium bromide (tetrazolium dye); PEG, poly(ethylene glycol); PVA, poly(vinyl alcohol); TEOS, tetraethoxysilane (cross linking agent); MIC, minimum inhibitory concentration; MRC-5, human-origin fibroblast cell line; Na-CMC, sodium carboxymethyl cellulose; NIH 3T3, mouse-origin fibroblast cell line.

AgNPs syntheses routes is also impressive, with the most common methods including chemical synthesis using either trisodium citrate,,${ }^{97,101,102}$ ascorbic acid, ${ }^{103,104}$ or sodium tetrahydridoborate $\mathrm{e}^{87,95,105}$ as a reducing agent, but also biosynthesis using natural extracts such as hyacinth plant leaves, ${ }^{106}$ Combretum erythrophyllum, ${ }^{107}$ Crinum latifolium, ${ }^{108}$ Curcuma longa, ${ }^{94}$ Fusarium verticillioides, ${ }^{99}$ or Sanghuangporus sanghuang. ${ }^{109}$ On the other hand, a frequently-applied route to obtain silver nanoparticles is simply mixing in a precursor (such as silver nitrate) into the polymer solution where simultaneous reduction of $\mathrm{Ag}^{+}$, formation of AgNPs and their stabilization takes place, ${ }^{92,93,110-112}$ due to the well-known ability of chitosan to reduce silver and to form a hydrogel with AgNPs at the same time. ${ }^{84,113}$ Aside from obvious advantages of this method being simplicity and avoidance of any reducing agents, one disadvantage could be the long reaction times (24 hours and more) needed to complete the synthesis. This is where the electrochemical synthesis comes in, as it provides an in situ and completely green method to reduce $\mathrm{Ag}^{+}$, while also allowing for additional reduction with chitosan to improve the yield of AgNPs in a much shorter timeframe. $^{34-36}$ All of the hydrogel formulations have exhibited very potent antibacterial activity range against a variety of bacteria such as Staphylococcus aureus (both methicillin-resistant and methicillin-susceptible), Escherichia coli, Pseudomonas aeruginosa, which was confirmed by various tests such as agar-diffusion, LIVE/ DEAD staining, minimum inhibitory and bactericidal concentration (MIC/MBC) as well as quantitative tests by counting colony forming units after exposure to tested samples (Table 1). Several studies have even confirmed the applicability of chitosan-based hydrogels as wound dressings through in vivo tests that confirmed accelerated healing of the wounds treated with these materials. ${ }^{93,96,97,109-111}$ Cytotoxicity, as an important factor for the potential clinical use of an antibacterial material, has also been tested against various cell lines (mostly fibroblasts or cancer-derived cells), and the results (where available) are overviewed in Table 1, showing generally good biocompatibility of chitosan-based wound dressings. An interesting study ${ }^{91}$ also compared the antibacterial activity and cytotoxicity effects of chitosan-PVP-AgNPs hydrogels to some commercial silver-based wound dressing materials such as ACTICOAT, Algivon, and Suprasorb $\mathrm{A}+\mathrm{Ag}$. This research indicated that, although the commercial coatings achieved the same or similar antibacterial activity against methicillin-resistant $S$ aureus (MRSA) and $E$ coli to the prepared hydrogel samples, their biocompatibility was much worse, and the viability of L929, HaCaT, and HDFa cells even dropped below $20 \%$ to $30 \%$. Thus, it can be observed that there is a vast potential to improve current proprietary and commercially-available wound dressing materials with significantly better ones. These are very good results as they indicate that the potential toxicity of AgNPs as a potent antibacterial agent can be circumvented by using a lower Ag concentration and leaning on its synergistic effect together with chitosan. ${ }^{36,90}$ Further, the controllability of the release behavior of AgNPs from chitosan-based hydrogels could also be an important factor, as seen in a recent article where even the hydrogels with higher AgNPs concentration exhibited no cytotoxicity, ${ }^{36}$ unlike previously tested PVA-based hydrogels without chitosan which showed serious dosedependent cytotoxicity with increased AgNPs content. ${ }^{31}$ This could be explained by better stabilization of AgNPs 
by chitosan and their controlled release over longer time periods, which not only enables prolonged antibacterial effect, but also helps curb the cytotoxicity issues. ${ }^{34-36}$

The formation of the hydrogel can be achieved by physical or chemical cross linking, depending on the properties of the chosen polymer(s), and the desired properties of the obtained hydrogel, such as cross linking degree, swelling ability, mechanical properties, and so on. The chemical cross linking involves gelation using chemical agents, and the obtained product is irreversible, meaning that it is insoluble and cannot be returned to sol state without breaking of chemical bonds. Chemical cross linking is relatively easy and quick, and allows facile control of the obtained hydrogel characteristics. ${ }^{114}$ However, a major problem with this method in the field of biomedical materials science is the threat of toxicity when using chemical cross linkers which are usually some organic solvents. For example, a very well-known cross linking agent for chitosan is glutaraldehyde, along with other aldehyde-based cross linkers, which are toxic and must be carefully washed out or extracted from the obtained hydrogel. ${ }^{115}$

A viable alternative are physical cross linking methods, which have also been shown to be very effective and efficient for obtaining hydrogel biomaterials. ${ }^{114}$ The main advantages of physical methods are nontoxicity of the obtained product, as well as reversibility of the hydrogels, which could be easily returned back to sol state under the right conditions, facilitating the biodegradability of the material. ${ }^{114}$ For example, poly(vinyl pyrrolidone) (PVP) is usually cross linked by radiation, ${ }^{86}$ yielding highly structurally and mechanically stable hydrogels with excellent properties. ${ }^{116}$ The cross linking is achieved by exposing the liquid polymer solution or dispersion to gamma radiation, which causes braking of chemical bonds within the polymer and the formation of free radicals, and their reactions with polymer chains create new intermolecular chemical bonds. ${ }^{10}$ Varying the irradiation dose and other parameters enables very accurate control of cross linking degree, as well as hydrogel properties. $^{116}$

On the other hand, by far the simplest physical cross linking method is freezing and thawing, which, as the name indicates is a facile method to obtain hydrogels of certain polymers (such as poly(vinyl alcohol), PVA) through several cycles of freezing and thawing. ${ }^{117,118}$ During freezing and thawing, the cross links between polymer chains are formed through hydrogen bonding, orientation into microcrystalline regions and by semipermanent entanglements. ${ }^{119}$ Thus, a physically cross linked hydrogel matrix is formed, which can be easily returned to the sol state-for example, PVA hydrogels can be dissolved in plain distilled water by heating to 80 to $90^{\circ} \mathrm{C} .{ }^{34}$ However, not all polymers can form hydrogels by this method - it has been shown that pure PVP ${ }^{120}$ hydrogels cannot be obtained by freezing and thawing, but PVP and CHI hydrogel blends with PVA can. ${ }^{34,120,121}$

Apart from hydrogels, the polymer-based wound dressings can be prepared in the form of thin films, which involves preparation of colloid solutions or dispersions, addition of antibacterial component, and finally casting and drying the solution to obtain free-standing films. This method was used to prepare films of $\mathrm{PVA}^{29,122} \mathrm{CHI},{ }^{123}$ and alginate (Alg), ${ }^{124}$ to mention but a few.

Hydrogels and films are two of the most frequent choices of form for polymer-based wound dressing materials, because of their facile preparation by abovementioned methods, and because of easy incorporation of antibacterial agent, allowing its long-term immobilization inside the polymer matrix, as well as sustained and controlled release to the wound site. This review will focus on several polymers (natural and synthetic) that have been most widely used for electrochemicallysynthesized AgNPs stabilization and delivery-PVA, PVP, alginate, and chitosan.

\section{3 | ELECTROCHEMICAL SYNTHESIS OF SILVER NANOPARTICLES AS A GREEN REDUCING METHOD}

As mentioned above, the electrochemical synthesis of silver nanoparticles bares several advantages over other reduction methods, including simple setup, facile control of reaction conditions, as well as nontoxicity of the used chemicals.

Several different methods for electrochemical synthesis of AgNPs have been reported in the literature. The first method involves the AgNPs synthesis in the colloid solution of polymers, with subsequent preparation of the desired form (film, hydrogel, or other), ${ }^{26-29,125,126}$ whereas in the second route hydrogels are prepared first, then swollen in the solution of $\mathrm{Ag}^{+}$precursor, and subsequently subjected to electrical current to obtain AgNPs synthesized in situ. ${ }^{30-36,127}$ Both methods will be briefly explained in the following subsections.

\section{1 | Galvanostatic method}

The first method, performed in colloid solutions of polymers with added $\mathrm{AgNO}_{3}$ as an ionic precursor, involves synthesis in galvanostatic regime, that is, applying constant current density to the working electrode over a 
short period of time. ${ }^{27}$ The principal scheme of the experimental setup is shown in Figure 1A. The apparatus consists of an electrochemical cell filled with the colloid solution mixed with $\mathrm{AgNO}_{3}$ at desired concentration, along with $\mathrm{KNO}_{3}$ which serves as a base electrolyte to improve conductivity. The cell contains two platinum plates serving as working and auxiliary electrodes, and a reference electrode (eg, a saturated calomel electrode, SCE), connected to a potentiostat used to supply constant current density. The reaction is carried out under $\mathrm{N}_{2}$ flow to remove the oxygen from the cell, while being constantly stirred on a magnetic stirrer in order to ensure uniformity of the concentrations in the colloid bulk. As the electrolyte is an aqueous solution, electrochemical reactions always include water electrolysis, that is, hydrogen evolution at the cathode (Equation 1) and oxygen evolution at the anode (Equation 2). The working electrode is a cathode; therefore the synthesis of AgNPs is achieved via cathodic reduction of silver ions (Equation 3). When the galvanostatic electrochemical synthesis is performed in aqueous solution around neutral $\mathrm{pH}$ and in the absence of stabilizing agents, the thermodynamically favored process is the electrochemical deposition of a macroscopic $\mathrm{Ag}$ layer on the cathode surface. ${ }^{27,29,128}$ This process is of course undesirable as it prevents formation and dispersion of AgNPs, and diminishes their yield in the solution. Therefore, in order to prevent this bulk cathodic deposition and to achieve a stable AgNP dispersion, stabilization agents are addedthe electrolyte is therefore an aqueous colloid solution of a polymer such as PVA or alginate. ${ }^{27,29}$ It has also been shown that other anodic side-reactions could occur due to the presence of polymers in the electrolyte, for example, to include oxidation of polymer components and their slight deposition on the anode surface, beside the oxygen evolution reaction. ${ }^{26,125}$ On the cathode however, the reactions are the same, that is, hydrogen evolution (Equation 1) and silver reduction (Equation 3). But now, due to the presence of stabilizing agents, the Ag atom clusters that form at the cathode can interact with polymer chains and move into the solution, ${ }^{27,29,128}$ which is why the synthesis is usually performed in an electrochemical cell with continuous stirring-to achieve uniform mass transfer and homogeneous distribution of the synthesized AgNPs across the electrolyte volume.
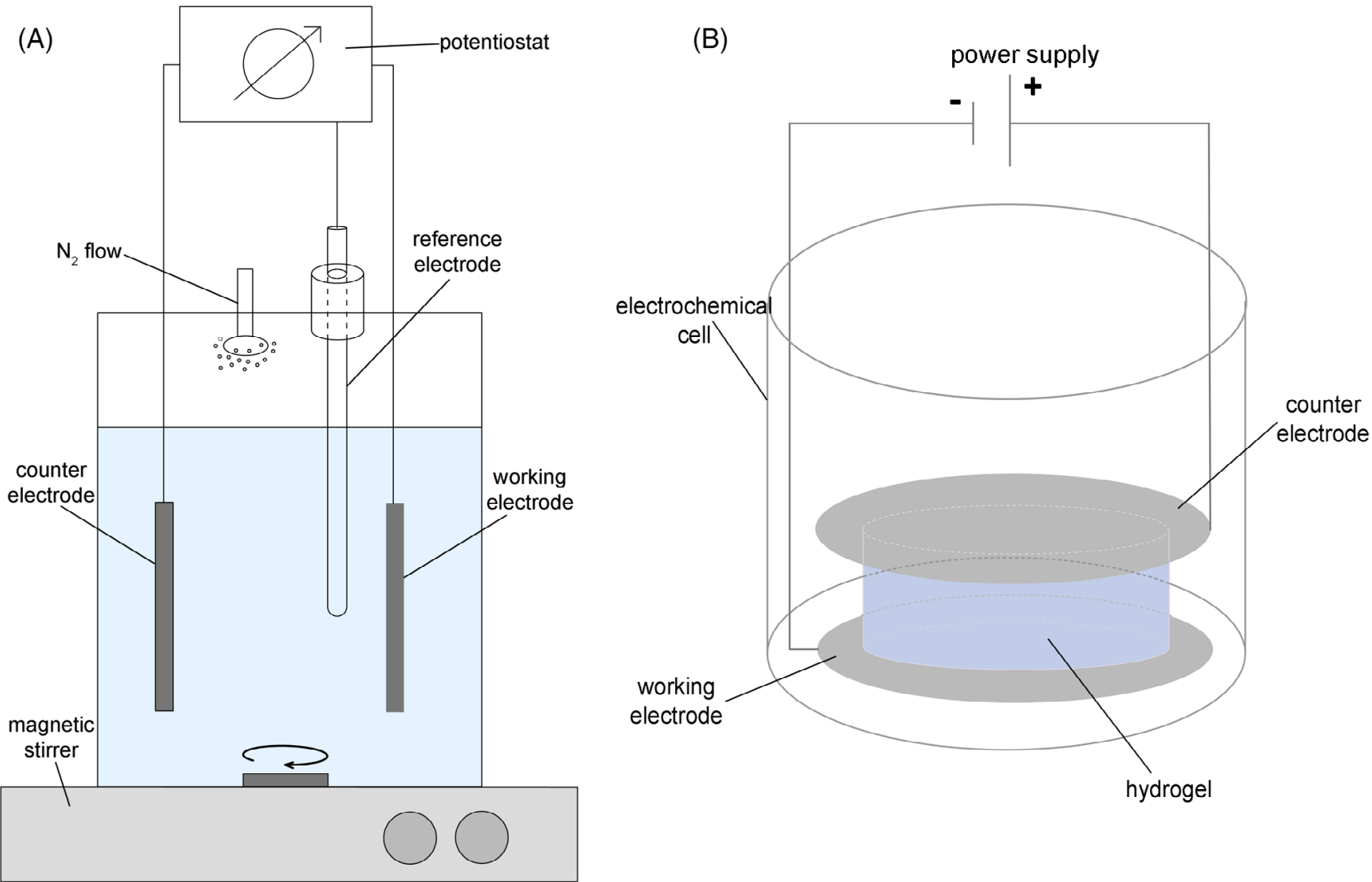

FI G U RE 1 Schematic representation of the electrochemical synthesis of silver nanoparticles in polymer-based colloid solutions, hydrogels and films: A, galvanostatic method, B, constant-voltage method [Color figure can be viewed at wileyonlinelibrary.com] 


$$
\begin{gathered}
2 \mathrm{H}_{3} \mathrm{O}^{+}+2 \mathrm{e}^{-} \rightarrow \mathrm{H}_{2}+2 \mathrm{H}_{2} \mathrm{O} \\
2 \mathrm{H}_{2} \mathrm{O} \rightarrow \mathrm{O}_{2}+4 \mathrm{H}^{+}+4 \mathrm{e}^{-} \\
n \mathrm{Ag}^{+}+n \mathrm{e}^{-} \rightarrow(\mathrm{Ag})_{n}
\end{gathered}
$$

Thus obtained colloid contains AgNPs which are shielded by polymers in the solution and are stable for long time periods. The colloid can then be cast into films,${ }^{29}$ extruded to microbeads, ${ }^{26,28,125}$ and microfibers, ${ }^{51}$ or cross linked to form hydrogels. ${ }^{28,29}$ This method has been used to obtain nanocomposites of different polymers, such as alginate, ${ }^{26,28,125} \mathrm{PVP},{ }^{120} \mathrm{PVA},{ }^{29}$ and their blends. ${ }^{120}$

\section{2 | Constant-voltage method}

The second electrochemical route of AgNPs synthesis involves first preparing the hydrogel by some of the abovementioned cross linking methods, followed by swelling of the obtained hydrogel in the $\mathrm{AgNO}_{3}$ solution (with $\mathrm{KNO}_{3}$ added to improve the electrical conductivity, as explained above). Equilibrium-swollen hydrogel is then placed between two platinum plates (working and counter electrodes) in a glass electrochemical cell, depicted in Figure 1B. The electrodes are connected to a DC power source, which supplies a constant voltage needed for the electrochemical synthesis of AgNPs. Thus, the swollen hydrogel serves as an electrolyte, and as the $\mathrm{AgNO}_{3}$ swelling medium is an aqueous solution, the main reaction is again water electrolysis, described by Equations (1) and (2). The synthesis of AgNPs takes place by the reduction of $\mathrm{Ag}^{+}$ions; however the process itself is likely slightly different than in the first method. As the hydrogel can be viewed mostly as a solid electrolyte, the reduction of silver ions by electrical current is most likely to result in a deposition of a bulk Ag layer on the cathode surface (Equation 4). ${ }^{33}$ This is of course undesirable, as the deposition of silver on platinum surface inevitably depletes the hydrogel of silver ions and lowers the yield of the synthesis. ${ }^{33-35}$ This is why the polarity of the electrodes during the synthesis is often reversed, as upon the polarity reversal the cathode becomes an anode, the bulk $\mathrm{Ag}$ layer on its surface is dissolved and the $\mathrm{Ag}^{+}$ions are replenished inside the hydrogel. ${ }^{33-35}$ Further, due to intensive hydrogen evolution on the cathode (Equation 1), the most likely formation of AgNP nucleation sites is achieved via reduction with $\mathrm{H}_{2}$ molecules inside the hydrogel (Equation 5). ${ }^{129}$

$$
\mathrm{Ag}^{+}+\mathrm{e}^{-} \rightarrow(\mathrm{Ag})_{\text {bulk }}
$$

$$
2 \mathrm{Ag}^{+}+\mathrm{H}_{2} \rightarrow 2(\mathrm{Ag})_{\mathrm{np}}+2 \mathrm{H}^{+}
$$

The AgNPs obtained by this method are stabilized inside the hydrogel matrix by interactions with polymer chains and incorporation in the matrix pores, which enables their long-term stabilization. The constantvoltage in situ electrochemical method was used to obtain AgNP-hydrogel nanocomposites with PVP, ${ }^{130,131}$ PVA, ${ }^{30-32}$ and PVA/CHI. ${ }^{33-35}$ Figure 2 depicts the representative synthetic workflow for the preparation of PVA/CHI hydrogels and the constant-voltage electrochemical synthesis of AgNPs to obtain Ag/PVA/CHI hydrogels. ${ }^{36}$ It should also be mentioned that potential drawbacks of electrochemical synthesis methods could comprise difficulties revolving around the process scaleup for commercial scope, as well as potential electricity costs, which could be avoided through careful process optimization and further research in this area.

\section{4 | POLYMER-BASED WOUND DRESSINGS WITH ELECTROCHEMICALLY INCORPORATED SILVER NANOPARTICLES AND THEIR PROPERTIES}

For either of the two above explained methods, the success rates of electrochemical synthesis, as well as the properties of the obtained silver nanoparticles and the wound dressing material itself, depend strongly on the type of polymer and its structure and form. For example, it has been shown that the yield of in situ electrochemical synthesis of AgNPs was increased in poly(vinyl alcohol)/chitosan/ graphene (PVA/CHI/Gr) hydrogel, compared to poly(vinyl alcohol)/graphene (PVA/Gr) hydrogel without chitosan, ${ }^{33}$ and the concentration of AgNPs in the hydrogel was higher with increased chitosan content. ${ }^{33,34}$ In this section, we aim to review the existing research on wound dressing materials with electrochemically synthesized silver nanoparticles and to compare their properties with a special focus on the concentration and characteristics of AgNPs and their biological properties.

Of course, different experimental conditions, such as the parameters of electrochemical synthesis and the concentration of the $\mathrm{AgNO}_{3}$ precursor, would be expected to have a profound impact on structure-property relationships of the obtained AgNPs. For example, the $\mathrm{Ag} /$ alginate $(\mathrm{Ag} / \mathrm{Alg})$ microbeads $^{26,28}$ were obtained by the galvanostatic method, whereby the AgNPs were synthesized in the alginate colloid solution, which was 
PVA<smiles>CC(C)CC(C)C</smiles>

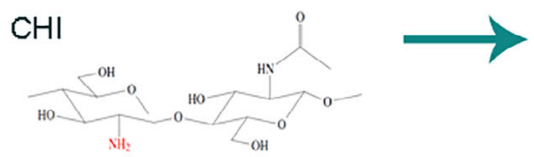

no bacterial growth

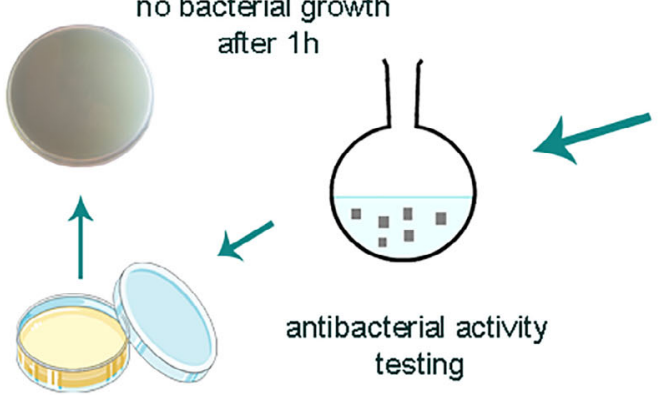

PVA/CHI hydrogel
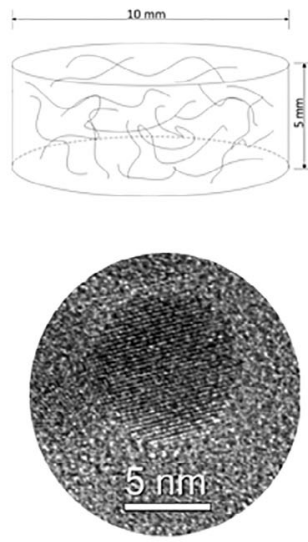

sub-10 nm

AgNPs
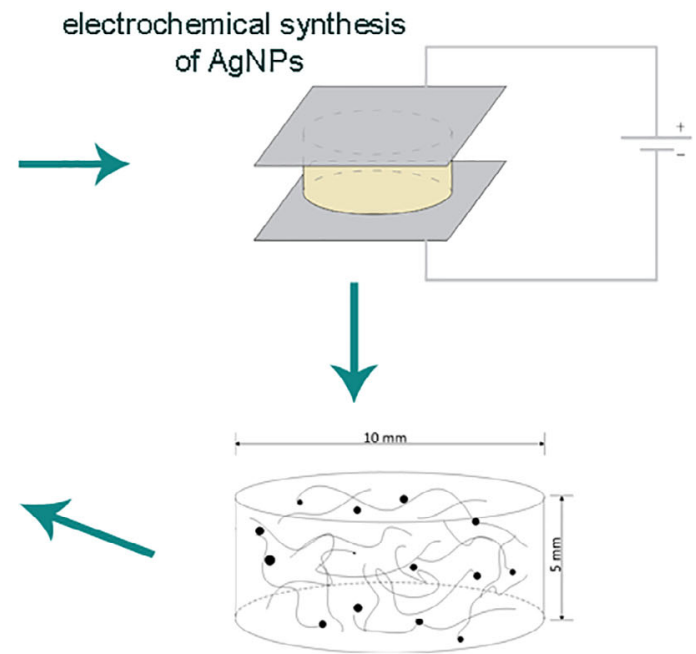

Ag/PVACHI hydrogel

F I G U RE 2 Schematic representation of the Ag/PVA/CHI hydrogel synthesis. Reprinted with permission from Reference 36 (c) 2019 Elsevier [Color figure can be viewed at wileyonlinelibrary.com]

extruded through a stainless steel needle, carrying a positive electrostatic charge $(6-8 \mathrm{kV})$, into the $\mathrm{Ca}\left(\mathrm{NO}_{3}\right)_{2}$ gelling bath. ${ }^{26,28}$ This innovative method allowed obtaining $\mathrm{Ag} / \mathrm{Alg}$ microbeads of controlled size and shape. ${ }^{27,125}$ The electrochemical synthesis of AgNPs was performed by applying a constant current density of $50 \mathrm{~mA} \mathrm{~cm}^{-2}$, implemented during 10 minutes. $^{26,28}$ On the other hand, $\mathrm{Ag} / \mathrm{PVA}$ and $\mathrm{Ag} / \mathrm{PVA} / \mathrm{Gr}$ colloid solutions $^{29}$ were obtained galvanostatically at $40 \mathrm{~mA} \mathrm{~cm}^{-2}$ during 30 minutes. Concerning the in situ electrochemical synthesis inside the hydrogel matrix, the experimental conditions for the synthesis of nanocomposite Ag/PVA, Ag/PVA/Gr, Ag/PVA/CHI, and Ag/PVA/CHI/Gr hydrogels were optimized at constant voltage of $90 \mathrm{~V}$, with 4 minutes implementation time $\mathrm{e}^{30,31,33,34}$ whereas the Ag/PVP hydrogels were synthesized at $200 \mathrm{~V}$ during 4 minutes. ${ }^{130}$

The first confirmation of successful incorporation of AgNPs and an estimate of their size and concentration is certainly UV-visible (UV-vis) spectroscopy, as AgNPs are well known for their optical properties, giving rise to distinct surface plasmon resonance (SPR) absorption band around $400 \mathrm{~nm}$. Some representative UV-vis spectra of AgNPs synthesized in different polymer carriers are illustrated in Figure $3 .^{28,29,36,130}$ The SPR band appears in UV-vis spectra of AgNPs as a consequence of their interaction with incident light, resulting in displacement of charges and polarization of the nanoparticles. ${ }^{132}$ The position, shape, and intensity of the SPR band depend strongly on the shape and size of AgNPs themselves, as well as on the dielectric properties of the surrounding medium. ${ }^{132}$ Further, the UV-vis spectrum could indicate the extent of agglomeration of AgNPs, as the larger particles and agglomerates give rise to bands at higher wavelengths $(>500 \mathrm{~nm}){ }^{24}$ This particular optical property of AgNPs has often been utilized to evaluate their concentration and size after electrochemical synthesis in colloid solutions or hydrogels. A comparison of the intensities (maximum absorbance, $\left.A_{\max }\right)$ of the SPR bands in wound dressing materials based on different polymers is presented in Figure $4 .{ }^{26,28,29,33,36,51,130,131}$ The data presented in Figure 4 depict clear differences among the yields of electrochemical synthesis and the variations are clearly dependent on the form of the material (colloid solution, microbeads, microfibers, or hydrogels).

As an illustration of the influence of implemented voltage on the synthesis success rate, the data in Figure 4 is presented for $\mathrm{Ag} / \mathrm{PVP}$ hydrogels synthesized at $200^{130}$ and $150 \mathrm{~V}^{131}$; the former clearly exhibiting higher maximum absorbance of the SPR peak, indicating higher concentration of AgNPs with increased applied voltage. Similarly, as already mentioned, the increase in chitosan content in $\mathrm{Ag} / \mathrm{PVA} / \mathrm{Gr}, \quad \mathrm{Ag} / \mathrm{PVA} / 0.1 \mathrm{CHI}, \quad \mathrm{Ag} / \mathrm{PVA} / 0.5 \mathrm{CHI}$, $\mathrm{Ag} / \mathrm{PVA} / 0.1 \mathrm{CHI} / \mathrm{Gr}$, and $\mathrm{Ag} / \mathrm{PVA} / 0.5 \mathrm{CHI} / \mathrm{Gr}$ hydrogels caused increased AgNPs concentration. ${ }^{33,36}$ Interestingly though, the presence of graphene also caused increase in AgNPs concentration, which is clearly visible comparing $\mathrm{Ag} / \mathrm{PVA} / 0.1 \mathrm{CHI}$ and $\mathrm{Ag} / \mathrm{PVA} / 0.5 \mathrm{CHI}$ with $\mathrm{Ag} / \mathrm{PVA} /$ $0.1 \mathrm{CHI} / \mathrm{Gr}$ and $\mathrm{Ag} / \mathrm{PVA} / 0.5 \mathrm{CHI} / \mathrm{Gr}$ hydrogels (Figure 4). It was shown before that graphene (or graphene oxide) could be successfully employed as dispersion agent to support AgNPs as it can affect their formation and stabilization inside polymer matrices. ${ }^{133-135}$ 
(A)

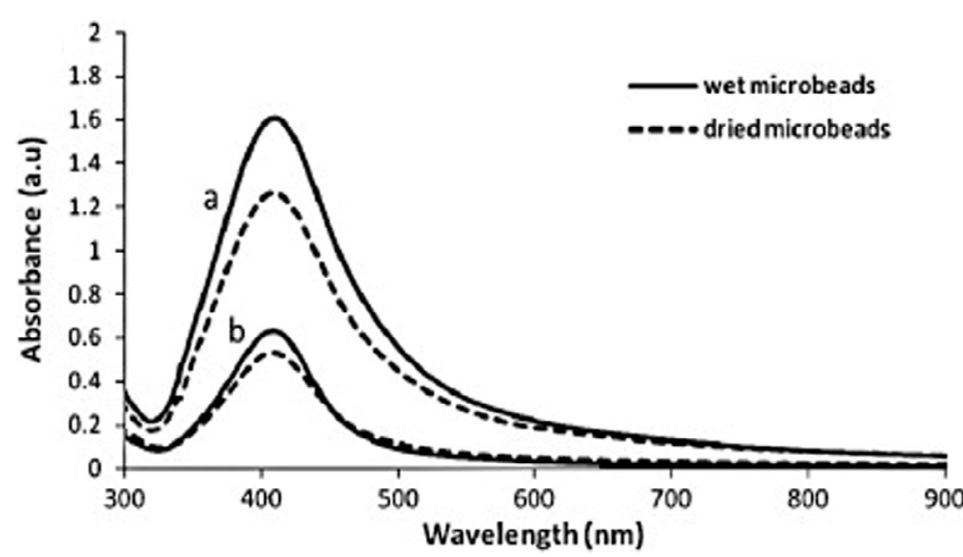

(C)

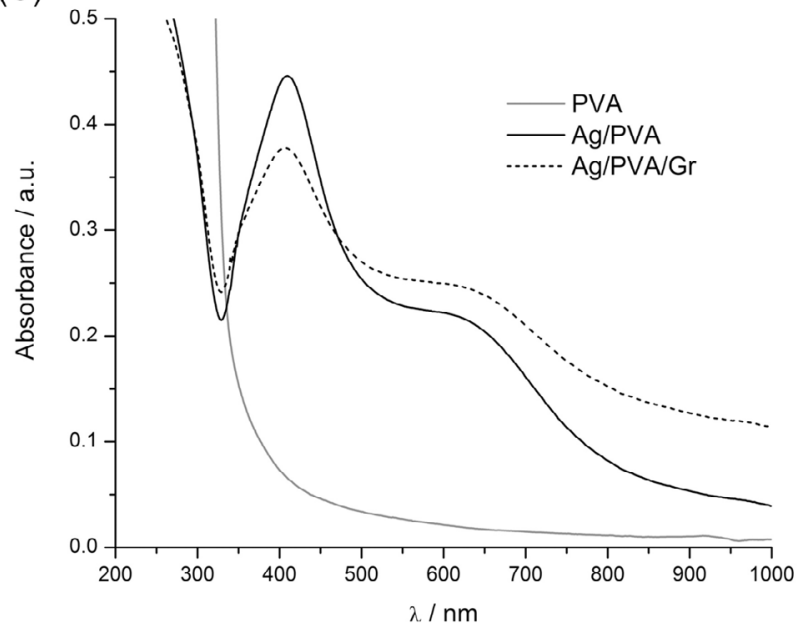

(B) 3

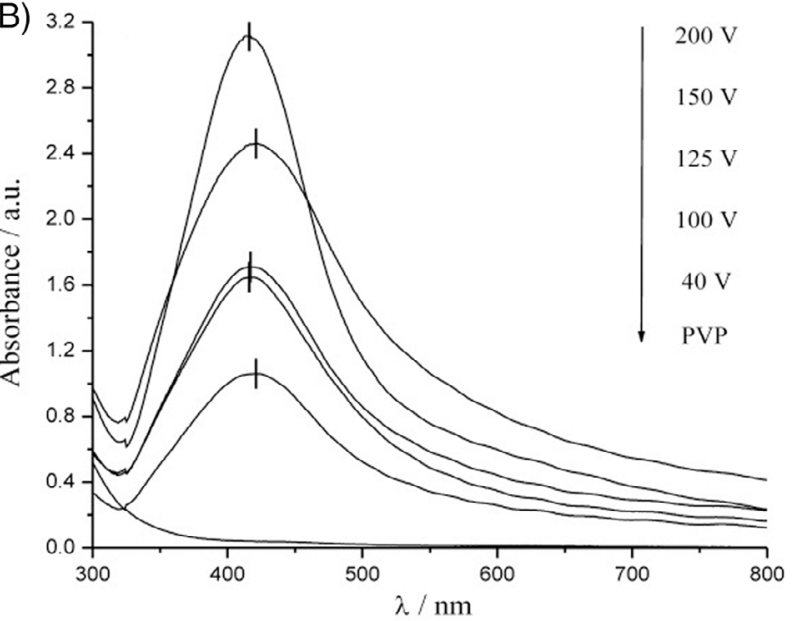

(D)

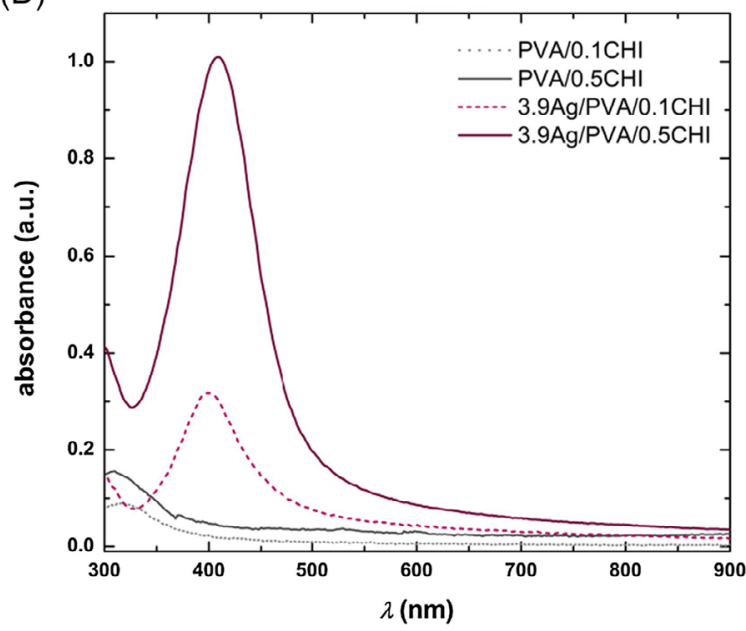

F I G U RE 3 Representative UV-vis spectra of AgNPs synthesized in: A, alginate microbeads (Reprinted with permission from Reference 28 @2014 Elsevier), B, PVP hydrogel (Reprinted with permission from Reference 130 @2014 Wiley), C, PVA and PVA/Gr hydrogels (Reprinted with permission from Reference 29 @2016 Elsevier) and D, PVA/CHI hydrogels (Reprinted with permission from Reference 36 (C)2019 Elsevier) [Color figure can be viewed at wileyonlinelibrary.com]

FI G URE 4 Comparison of the absorbance $\left(A_{\max }\right)$ of the UV-vis plasmon resonance absorption maxima of silver nanoparticles in different polymer matrices. Data obtained from References 26,28,29,33,36,51,130,131

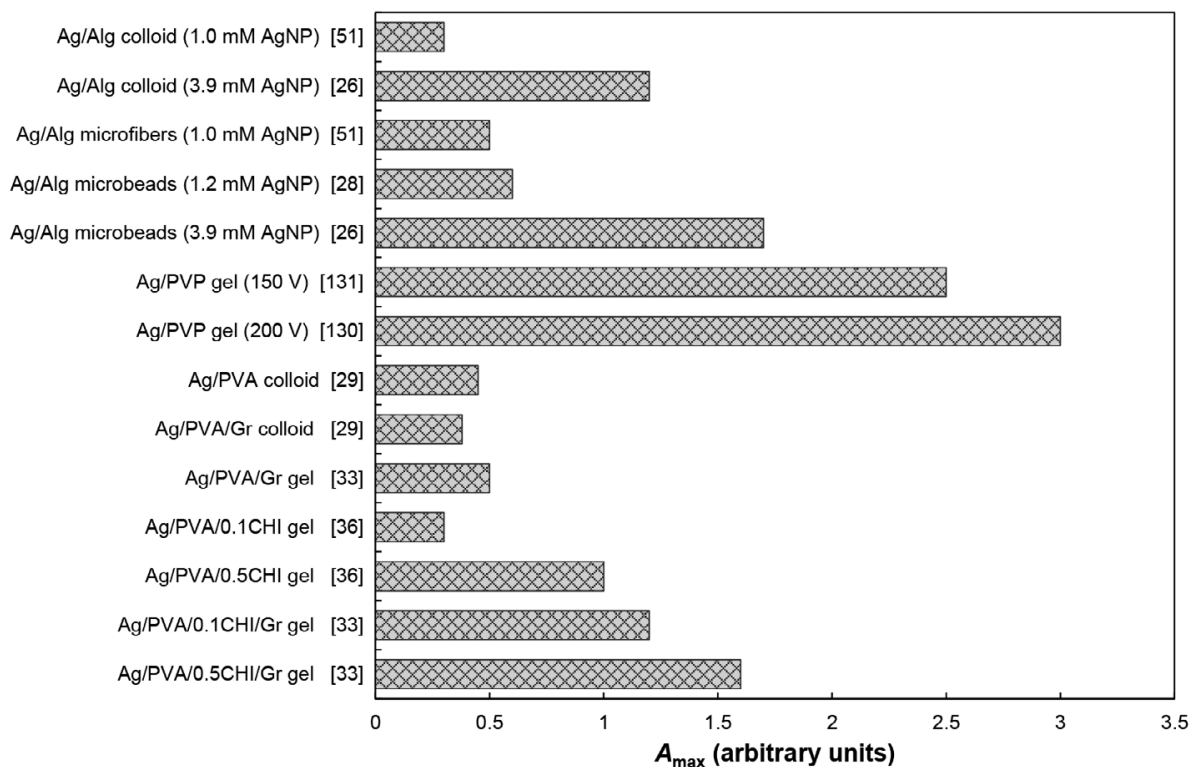


More comprehensive indication of AgNPs size, shape and morphology is transmission electron microscopy (TEM). The TEM micrographs of silver nanoparticles (Figure 5) in Ag/PVA and Ag/PVA/Gr colloid dispersions showed sphere-like morphologies of AgNPs with sizes in the range 10 to $40 \mathrm{~nm},{ }^{29}$ whereas the AgNPs in $\mathrm{Ag} / \mathrm{Alg}$ colloids and microbeads were found to be spherical with 10 to $30 \mathrm{~nm}$ diameters. ${ }^{26}$ It is well known that the size of AgNPs strongly affects their antibacterial properties-the smaller the nanoparticles, the stronger antibacterial effect they exhibit. ${ }^{136}$ AgNPs incorporated in Ag/PVA/CHI and $\mathrm{Ag} / \mathrm{PVA} / \mathrm{CHI} / \mathrm{Gr}$ hydrogels (Figure 5C,D) were also characterized by high-resolution TEM (HRTEM) and they were found to vary in size, with larger nanoparticles in the range of 10 to $20 \mathrm{~nm}$, but with much smaller AgNPs present, even down to $\approx 2$ to $5 \mathrm{~nm}$ for $\mathrm{Ag} / \mathrm{PVA} / 0.5 \mathrm{CHI} /$ Gr hydrogels. ${ }^{35,36}$

Another optical technique, dynamic light scattering (DLS), is a reliable method to evaluate the statistical distribution of silver nanoparticle sizes, that is, their hydrodynamic diameter in polymer dispersions. Figure 6 represents the comparison of Z-average hydrodynamic diameters, $D_{\mathrm{H}}$, for four types of hydrogels-3.9Ag/ PVA/0.1CHI, 3.9Ag/PVA/0.5CHI, 3.9Ag/PVA/0.1CHI/ $\mathrm{Gr}$, and 3.9Ag/PVA/0.5CHI/Gr. ${ }^{35,36}$ From Figure 6, it can be observed that the nanoparticle sizes were smaller than $10 \mathrm{~nm}$ in the case of all four samples, which is highly favorable for antibacterial efficiency of the obtained hydrogel wound dressings, as the antibacterial properties of AgNPs are well known to be strongly size-dependent. ${ }^{137,138}$ There was no noticeable effect of Gr on the nanoparticle size distribution; however, the effect of CHI content is obvious, as the hydrogels with $0.5 \mathrm{wt} \% \mathrm{CHI}$ exhibited smaller $D_{\mathrm{H}}(\approx 6 \mathrm{~nm})$, compared to those with $0.1 \mathrm{wt} \%$ CHI (7-8 nm). ${ }^{35,36}$

An important, and often quite difficult to determine, property of AgNP-containing hydrogel materials is certainly the distribution of AgNPs along the hydrogel matrix. The aim is generally to obtain uniformlydistributed AgNPs, which is quite important for many characteristics of wound dressings, such as antibacterial activity and silver release. Usually, the spatial
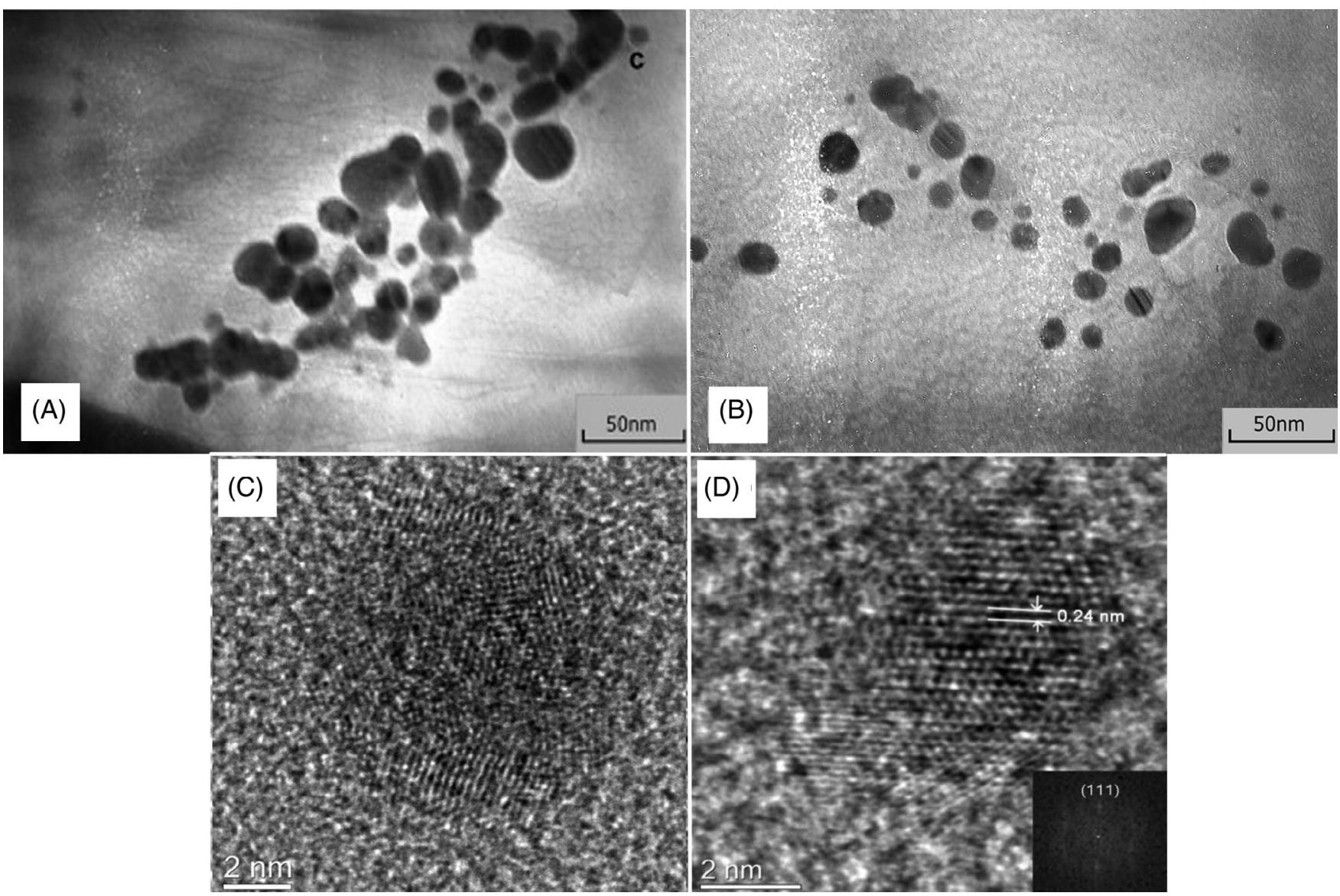

F I G U RE 5 Representative TEM micrographs of AgNPs in: A, Ag/alginate microbeads (reprinted with permission from Reference 26 (C2019 Elsevier), B, Ag/PVA/Gr hydrogel (reprinted with permission from Reference 29 (C2019 Elsevier), C, Ag/PVA/0.5CHI hydrogel (reprinted with permission from Reference 36 (C2019 Elsevier) and (D) Ag/PVA/0.5CHI/Gr hydrogel (reprinted with permission from Reference 35 (c)2019 Elsevier) 
distribution of AgNPs can be evaluated by microscopic techniques, such as scanning electron microscopy. ${ }^{139}$ Jovanovic et $\mathrm{al}^{130}$ took an interesting approach, where the top layers of Ag/PVP hydrogels (with electrochemically synthesized AgNPs) were cut off and the remaining discs were analyzed by cyclic voltammetry in order to confirm uniform distribution of nanoparticles along the hydrogel volume. Other than the spatial distribution, size distribution of AgNPs is another important factor to consider for silver-loaded wound dressings. The size distribution of AgNPs can be determined using TEM analysis, but DLS measurements also provide more statisticallyrelevant average size values and size distributions. The size distribution of electrochemically synthesized (galvanostatic method) AgNPs in Ag/Alg colloid solutions and hydrogels was evaluated by TEM imaging and the distribution was found to be fairly narrow for colloids and hydrogels based on low-viscosity alginate, in the 3 to $18 \mathrm{~nm}$ range, with average values around 8 to $9 \mathrm{~nm} .{ }^{140}$ On the other hand, medium-viscosity alginate hydrogels and colloids contained a broader AgNPs size distribution (3-28 nm), with larger average particle diameters $(9-12 \mathrm{~nm}),{ }^{140}$ indicating that the choice and properties of the polymer matrix play an important role in controlling the AgNPs characteristics. Similar results were obtained for chitosan-containing hydrogels, which were analyzed by DLS as also discussed above. The statistically-averaged, intensity-weighted size distributions of electrochemically synthesized AgNPs (constant-voltage method) in 3.9Ag/PVA/0.1CHI, 3.9Ag/PVA/0.5CHI, 3.9Ag/ PVA/0.1CHI/Gr, and 3.9Ag/PVA/0.5CHI/Gr hydrogels, were found to be monomodal, and quite narrow in the 2 to $11 \mathrm{~nm}$ range. ${ }^{35,36}$ Interestingly though, volumeweighted AgNP size distribution in the 3.9Ag/

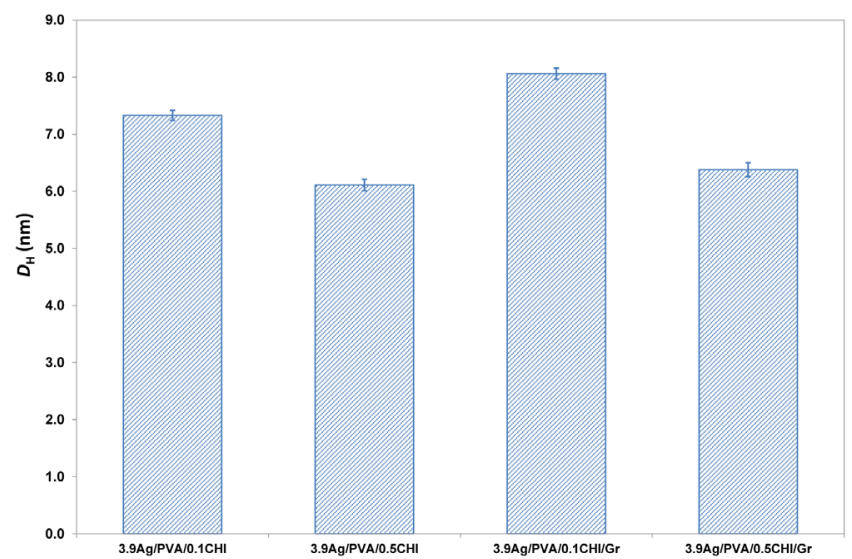

F I G U RE 6 Comparison of the Z-average nanoparticle sizes (hydrodynamic diameters, $D_{\mathrm{H}}$ ) extracted from DLS data for different hydrogels ${ }^{35,36}$ [Color figure can be viewed at wileyonlinelibrary.com]
PVA/0.5CHI/Gr hydrogel was found to be actually bimodal $-87.0 \%$ by volume were in the $1.76 \mathrm{~nm}$ group, whereas the rest were in the $8.22 \mathrm{~nm}$ group. ${ }^{35}$ These results could suggest a strong influence of both graphene presence and chitosan content on AgNPs size, stability and size distribution. Finally, the electrochemicallysynthesized AgNPs size distributions in Ag/PVP hydrogel discs were evaluated using scanning electron microscopy, and the obtained results indicated broader distribution $(40-120 \mathrm{~nm})$ with average size around $\approx 75 \mathrm{~nm},{ }^{130}$ highlighting again the importance of the role the polymer plays in controlling this particular property of AgNPs.

Based on the discussion provided above, it can be concluded that the electrochemical synthesis methods enable facile and efficient control of the AgNPs yield, that is, their concentration in the obtained wound dressing material, as well as their sizes and size distributions, by varying different parameters of the synthesis (such as the synthesis mode, that is, constant-voltage or galvanostatic, implementation voltage, or current and time). The properties of the obtained AgNPs can also be controlled and tailored through careful and adequate choice of polymers and/or blends that make up the dressing material, which demonstrates the versatility of the electrochemical AgNP synthesis routes.

\section{1 | Mechanical properties}

An important characteristic of wound dressing materials are certainly mechanical properties, especially in the long-lasting wound treatment conditions, where deterioration of the dressing material would lead to worsened barrier properties of the dressing. Therefore, it is crucial that the dressing be able to endure the loads under real usage conditions, and exhibit good mechanical properties, such as high elastic and/or compressive strength and modulus. It is also desirable that these properties mimic those of the skin tissue in vivo, in order to avoid mismatch of the elastic properties of the dressing and the surrounding skin, and to exert minimal distress on the newly-formed epidermis around the wound. ${ }^{141}$ The in vivo torsion tests, performed on different samples of human skin (male and female, different age groups), indicated the orders of magnitude for tensile properties0.42 to $0.85 \mathrm{MPa}$ for Young's elastic modulus, with increase in these values (correlated with increased skin rigidity) observed in older age groups. ${ }^{142}$

Graphene, which is often utilized as a mechanical strength-improving filler, was shown to improve tensile properties of wound dressings with electrochemically synthesized AgNPs-Ag/PVA/Gr films exhibited higher tensile strength (141.1 $\pm 0.4 \mathrm{MPa})$ as well as Young's 
elastic modulus $(0.701 \pm 0.039 \mathrm{GPa})$, compared to $\mathrm{Ag} / \mathrm{PVA}$ (tensile strength $121.2 \pm 2.5 \mathrm{MPa}$, Young's elastic modulus $0.309 \pm 0.059 \mathrm{GPa}),{ }^{29}$ indicating that the addition of graphene caused improved strength of the films, but decreased elasticity. On the other hand, tensile strength of $\mathrm{Ag} / \mathrm{PVA} / \mathrm{Gr}$ films was slightly lower in comparison with PVA/Gr film without AgNPs $\left(177.9 \pm 4.8 \mathrm{MPa}^{122}\right)$, indicating that silver loading could impact the mechanical properties of the wound dressings, presumably due to the binding to the polymer matrix causing slight rigidity and decreasing mechanical capabilities. Further, films with chitosan exhibited notably lower tensile strength (30.7, 22.6, and $78.0 \mathrm{MPa}$ for PVA/0.1CHI, PVA/0.5CHI, and PVA/0.5CHI/Gr, respectively), as well as Young's elastic modulus (21.4, 14.0, and 121.7 $\mathrm{MPa}$, respectively), ${ }^{35}$ compared to those without chitosan as outlined above, underlining the effect of chitosan on the mechanical behavior of wound dressings-causing higher brittleness but improved elasticity. However, all of the above-mentioned Young's elastic modulus values remained close to or higher than those measured for human skin in vivo (0.4-0.8 $\mathrm{MPa}^{142}$ ) pointing to strong potential of different polymer materials to successfully protect the wounds long term.

Another method to evaluate the mechanical properties of wound dressing materials is bioreactor evaluation that is an in vitro method to mimic more closely in vivo conditions, ${ }^{22,28}$ that is, to evaluate the mechanical behavior of materials under dynamic compression close to that in physiological conditions. PVP and Ag/PVP hydrogels were evaluated under these conditions, and it was found that the presence of AgNPs led to a slight decrease in elasticity of Ag/PVP hydrogel (dynamic compression modulus $48.4 \mathrm{kPa}$ ), compared to PVP (dynamic compression modulus $37.6 \mathrm{kPa}$ ), whereas the compression stress was found to be a linear function of the applied strain. ${ }^{130}$ Further, the equilibrium unconfined compression moduli (which were obtained in the bioreactor at sequential increments of $50 \mu \mathrm{m}$ displacement while allowing 30 minutes pause between the increments to reach equilibrium) were measured for PVP (26-27 kPa) and Ag/PVP hydrogel discs $(30-55 \mathrm{kPa}),{ }^{10}$ and the general trend observed was the same when it comes to the influence of AgNPs loading on the polymer matrix. Similar results were obtained for of Ag/alginate discs as well as packed microbead beds, with equilibrium unconfined compression moduli values being 9.4 and $31.6 \mathrm{kPa}$, respectively. ${ }^{128,143}$

The results of the above-discussed research works certainly showed that mechanical and elastic properties of wound dressing materials could vary with respect to different polymers and their contents, as well as due to the influence of AgNPs loading; however they also confirmed that these materials with electrochemically synthesized AgNPs exhibited good mechanical behavior and elasticity, and could therefore be seriously considered for longlasting wound dressing materials.

\section{2 | Swelling and silver release properties}

An important property of hydrogel for wound dressing applications is its swelling behavior, as it influences the exudate sorption characteristics, as well as the ability to maintain the local moisture and to prevent excessive drying of the wound. Therefore an unavoidable part of any hydrogel wound dressing research is swelling study. Usually, the swelling properties for prospective wound dressing materials are evaluated in simulated physiological conditions, that is, in one of the biologically-relevant saline media and at $37^{\circ} \mathrm{C}$. The most frequently evaluated parameters are sorption curves and diffusion coefficients of the swelling medium through the hydrogel matrix. The $D_{\text {medium }}$ values are usually calculated by fitting the sorption curves with some literature model listed in Table 2. In Table 3, a comparison of diffusion coefficients of the swelling medium $\left(D_{\text {medium }}\right)$ is presented for different hydrogels (with and without AgNPs) based on poly(vinyl pyrrolidone), poly(vinyl alcohol), and chitosan.

Comparing the diffusion coefficients, $D_{\text {medium }}$, of the swelling medium through the hydrogel matrix, a clear trend was observed for hydrogels made from different polymers (Table 3). The order of magnitude of $D_{\text {medium }}$ for PVP-based hydrogels was $\approx 10^{-4} \mathrm{~cm}^{2} \mathrm{~s}^{-1},{ }^{130}$ it decreased to $\approx 10^{-6} \mathrm{~cm}^{2} \mathrm{~s}^{-1}$ for Ag/PVA and Ag/PVA/ $\mathrm{Gr}^{31}$ and finally decreased again to $\approx 10^{-8} \mathrm{~cm}^{2} \mathrm{~s}^{-1}$ for chitosan-containing hydrogels. ${ }^{34,35}$ The decrease of the swelling medium diffusion coefficients could indicate slower swelling of the hydrogels, which could be due to higher cross linking degree of the polymer matrix, causing slower uptake of the swelling medium, which is usually some physiologically-relevant buffer solution.

While the variations in $D_{\text {medium }}$ values indicated differences in the hydrogel matrix properties and their different swelling behavior, it should also be noted that they were obtained based on the appropriate swelling models. Specifically, in order to calculate diffusion coefficient, the sorption curves must be fitted with some theoretical model, based on Fick's diffusion law(s). The most frequently used model is an early-time approximation (ETA), ${ }^{130,144}$ which allows the $D_{\text {medium }}$ calculation from the slope of a reduced sorption curve (ie, dependence of fraction of absorbed medium $v s$ square root of time). This method was used to calculate $D_{\text {medium }}$ for PVP, Ag/PVP, 
Ag/PVA, and Ag/PVA/Gr hydrogels. ${ }^{31,130}$ On the other hand, Ritger and Peppas ${ }^{145}$ have proposed a modified equation for ETA model (Table 2), which is more appropriate for swelling of thick hydrogel discs. An illustration of the differences between the standard and modified ETA models is shown in Figure $7,{ }^{35}$ and shows that the modified ETA extends the predictability of swelling behavior up to $90 \%$ of swelling. Conversely, late-time approximation is often used to model the swelling behavior at the last $40 \% .{ }^{144,146,147}$ Even more appropriate model is the Etters equation (Table 2), ${ }^{146}$ which encompasses the entire swelling period, and which was used to obtain the $D_{\text {medium }}$ for chitosan-containing hydrogels. ${ }^{35}$

An important property of hydrogel wound dressings, especially from antibacterial application standpoint, is certainly silver release behavior. Several representative silver release profiles for different hydrogel formulations (Ag/PVP, Ag/PVA, Ag/PVA/Gr, and Ag/PVA/CHI/Gr) are depicted in Figure 8. All of the AgNPs-containing hydrogels exhibited particular release profiles, specifically "burst release" in the initial period, followed by reaching a plateau of slower release up to 28 days. $^{28-31,34,35,130}$ The initial fast release of the antibacterial agent is certainly favorable in the sense that it helps achieve immediate sterility of the wound and prevents the formation of biofilm, whereas the later slower release ensures that sterility and antibacterial properties of the dressing are maintained for a long period of time. ${ }^{148,149}$ On the other hand, the duration of the initial "burst" period dictates the frequency of dressing replacement, and thus it is desirable that this initial period last as long as possible, in order to minimize the need for frequent replacement, all the while ensuring that potent antibacterial properties are retained. For example, the plateau for $\mathrm{Ag} / \mathrm{PVP},{ }^{130} \mathrm{Ag} / \mathrm{PVA}$, and $\mathrm{Ag} / \mathrm{PVA} / \mathrm{Gr}^{29-31,130}$ hydrogels was reached after 3 to 4 days, whereas for chitosan-containing hydrogels ${ }^{34,35}$ this period was extended up to 5 to 7 days due to stabilization of AgNPs by interactions with chitosan (Figure 8).
This indicated that the presence of chitosan improved the release properties of PVA-based hydrogels.

Of course, the problem of potential cytotoxicity is always a concern when AgNPs are used as antibacterial agents, therefore this must be taken into account when analyzing the release profiles, especially in the initial "burst" period. A good indication of the amount of released silver is the percentage of release after 48 hours, and the comparison of these data for different hydrogels is presented in Table 4. As can be observed, the proportion of the released silver with respect to initial concentration of AgNPs depends on the type of polymer, as well as the concentration of AgNPs themselves. For example, $\mathrm{Ag} / \mathrm{Alg}$ microbeads released up to $50 \%$ of silver during

T A B L E 3 Diffusion coefficients of medium during swelling of different hydrogels at $37^{\circ} \mathrm{C}$

\begin{tabular}{|lll} 
Sample & $\boldsymbol{D}_{\text {medium }}\left(\mathbf{c m}^{\mathbf{2}} \mathbf{s}^{-\mathbf{1}}\right)$ & References \\
\hline $\mathrm{PVP}$ & $1.23 \times 10^{-4}$ & {$[130]$} \\
$\mathrm{Ag} / \mathrm{PVP}$ & $1.33 \times 10^{-4}$ & {$[130]$} \\
$\mathrm{Ag} / \mathrm{PVA}$ & $6.10 \times 10^{-6}$ & {$[31]$} \\
$\mathrm{Ag} / \mathrm{PVA} / \mathrm{Gr}$ & $7.80 \times 10^{-6}$ & {$[31]$} \\
\hline $\mathrm{PVA} / 0.1 \mathrm{CHI}$ & $1.80 \times 10^{-8}$ & {$[36]$} \\
\hline $\mathrm{PVA} / 0.5 \mathrm{CHI}$ & $3.53 \times 10^{-8}$ & {$[36]$} \\
\hline $\mathrm{PVA} / 0.1 \mathrm{CHI} / \mathrm{Gr}$ & $3.12 \times 10^{-8}$ & {$[34,35]$} \\
\hline $\mathrm{PVA} / 0.5 \mathrm{CHI} / \mathrm{Gr}$ & $3.53 \times 10^{-8}$ & {$[34,35]$} \\
\hline $0.25 \mathrm{Ag} / \mathrm{PVA} / 0.1 \mathrm{CHI}$ & $0.828 \times 10^{-8}$ & {$[36]$} \\
\hline $0.25 \mathrm{Ag} / \mathrm{PVA} / 0.5 \mathrm{CHI}$ & $0.738 \times 10^{-8}$ & {$[36]$} \\
\hline $3.9 \mathrm{Ag} / \mathrm{PVA} / 0.1 \mathrm{CHI}$ & $1.42 \times 10^{-8}$ & {$[36]$} \\
\hline $3.9 \mathrm{Ag} / \mathrm{PVA} / 0.5 \mathrm{CHI}$ & $2.20 \times 10^{-8}$ & {$[36]$} \\
\hline $0.25 \mathrm{Ag} / \mathrm{PVA} / 0.1 \mathrm{CHI} / \mathrm{Gr}$ & $1.74 \times 10^{-8}$ & {$[34,35]$} \\
\hline $0.25 \mathrm{Ag} / \mathrm{PVA} / 0.5 \mathrm{CHI} / \mathrm{Gr}$ & $2.36 \times 10^{-8}$ & {$[34,35]$} \\
\hline $3.9 \mathrm{Ag} / \mathrm{PVA} / 0.1 \mathrm{CHI} / \mathrm{Gr}$ & $0.940 \times 10^{-8}$ & {$[35]$} \\
\hline $3.9 \mathrm{Ag} / \mathrm{PVA} / 0.5 \mathrm{CHI} / \mathrm{Gr}$ & $0.983 \times 10^{-8}$ & {$[35]$} \\
\hline
\end{tabular}

T A B L E 2 The most frequently used models for swelling data fitting and calculation of medium diffusion coefficients

\begin{tabular}{|c|c|c|c|}
\hline Name of the model & Equation & Range of use & References \\
\hline Standard ETA & $\frac{q_{\mathrm{t}}}{q_{\mathrm{eq}}}=4\left(\frac{D_{\mathrm{ETA}} t}{\pi \delta^{2}}\right)^{1 / 2}$ & $<60 \%$ swelling & {$[144,147]$} \\
\hline Modified ETA & $\begin{aligned} \frac{q_{\mathrm{t}}}{q_{\mathrm{eq}}} & =4\left(\frac{D_{\mathrm{ETA}} t}{\pi r^{2}}\right)^{\frac{1}{2}}-\pi\left(\frac{D_{\mathrm{ETT}} t}{\pi r^{2}}\right)-\frac{\pi}{3}\left(\frac{D_{\mathrm{ETA}} t}{\pi r^{2}}\right)^{\frac{3}{2}} \\
& +4\left(\frac{D_{\mathrm{ETA}} t}{\pi \delta^{2}}\right)^{\frac{1}{2}}-\frac{2 r}{\delta}\left[8\left(\frac{D_{\mathrm{ETA}} t}{\pi r^{2}}\right)-\right. \\
- & \left.2 \pi\left(\frac{D_{\mathrm{ETTA}} t}{\pi r^{2}}\right)^{3 / 2}-\frac{2 \pi}{3}\left(\frac{D_{\mathrm{E}} A t}{\pi r^{2}}\right)^{2}\right]\end{aligned}$ & Up to $80 \%$ to $90 \%$ swelling & {$[35,36,145]$} \\
\hline LTA & $\frac{q_{\mathrm{t}}}{q_{\mathrm{eq}}}=1-\frac{8}{\pi^{2}} \exp \left(-\frac{D_{\mathrm{LTA}} \pi^{2} t}{\delta^{2}}\right)$ & $>60 \%$ swelling & {$[144,146,147]$} \\
\hline Etters & $\frac{q_{\mathrm{t}}}{q_{\mathrm{eq}}}=1-\exp \left[-k\left(\frac{D t}{\delta^{2}}\right)^{a}\right]^{1 / b}$ & Entire range & {$[144,146,147]$} \\
\hline
\end{tabular}


(A)

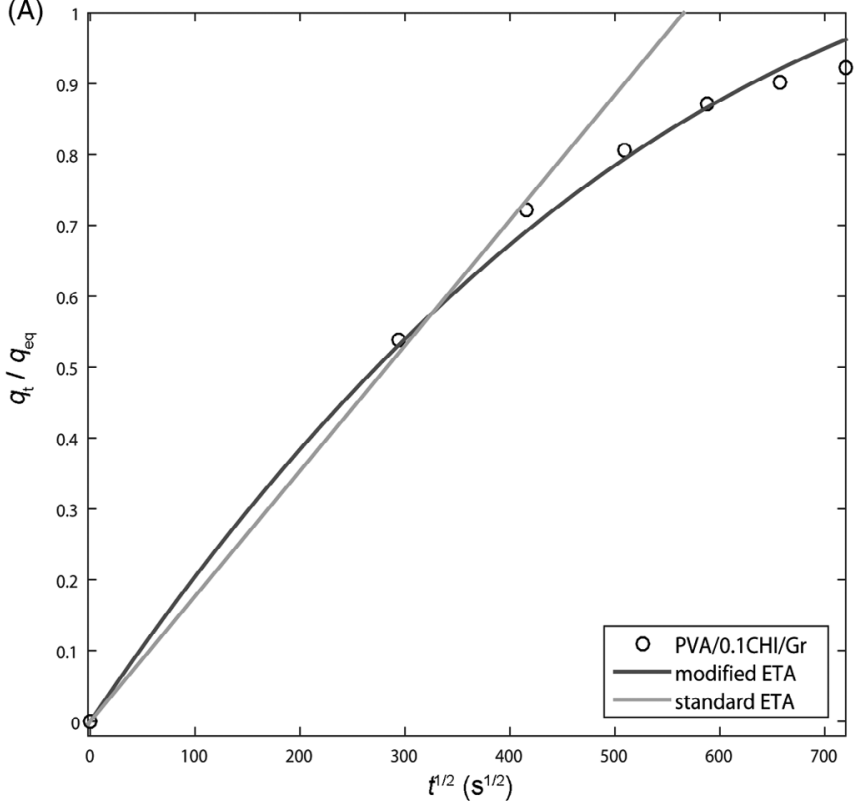

(B)

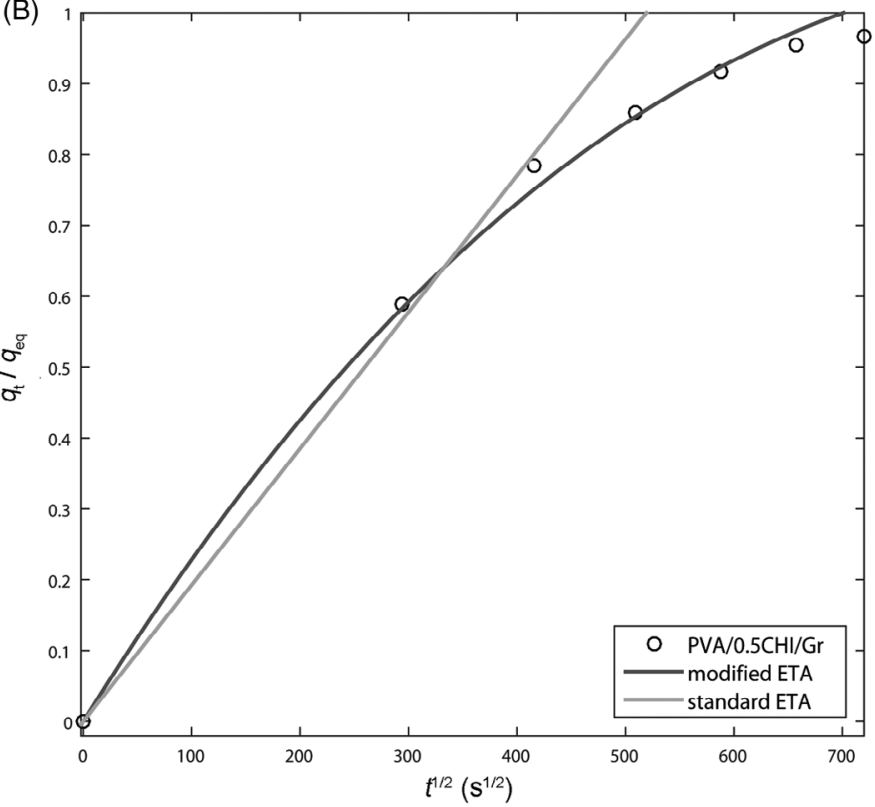

FI G U RE 7 Comparison of different ETA models of swelling on the example of A, PVA/0.1CHI/Gr and B, PVA/0.5CHI/Gr hydrogels. Reprinted with permission from Reference 35 (C) 2019 Elsevier

the first 2 days, ${ }^{28}$ whereas the Ag/PVP hydrogel (obtained by in situ constant-voltage electrochemical reduction in hydrogel preswollen in $3.9 \mathrm{mM} \mathrm{AgNO}_{3}$ solution) released $\approx 60 \%$ of initial AgNPs. ${ }^{130}$ Further, Ag/PVA and Ag/PVA/ $\mathrm{Gr}$ hydrogels, obtained by galvanostatic reduction in colloid solution, followed by hydrogel cross linking, released less than $20 \%$ in the initial 2 days, ${ }^{29}$ while the same hydrogels, obtained by in situ electrochemical synthesis in the hydrogel released $\approx 25 \%$ in the same period. ${ }^{31}$ Moreover, the same Ag/PVA and Ag/PVA/Gr hydrogels, with AgNPs synthesized at constant voltage in the hydrogel swollen in higher concentration of $\mathrm{AgNO}_{3}(1.0 \mathrm{mM})$, released even higher amounts of silver, that is, $48 \%$ and $63 \%$, respectively. ${ }^{30}$ Similar trend was observed for chitosan-containing hydrogels, where $0.25 \mathrm{Ag} /$ PVA/0.1CHI/Gr (0.25 mM $\mathrm{AgNO}_{3}$ swelling solution) released lower amount of $\mathrm{Ag}$ in 48 hours $(\approx 22 \%),{ }^{34} \mathrm{com}-$ pared to $3.9 \mathrm{Ag} / \mathrm{PVA} / 0.1 \mathrm{CHI} / \mathrm{Gr}(\approx 60 \%) .{ }^{35}$ The effect of chitosan content on the stabilization of AgNPs was clearly visible here-the hydrogels with more CHI (0.5 wt\%) released much lower amounts of silver in 48 hours $\left(\approx 12 \%\right.$ for $0.25 \mathrm{Ag} / \mathrm{PVA} / 0.5 \mathrm{CHI} / \mathrm{Gr}^{34}$ and $\approx 28 \%$ for $3.9 \mathrm{Ag} / \mathrm{PVA} / 0.5 \mathrm{CHI} / \mathrm{Gr}^{35}$ ), compared to those with $0.1 \mathrm{wt} \% \mathrm{CHI}$. Also, hydrogels without graphene exhibited similar trends, with $0.25 \mathrm{Ag} / \mathrm{PVA} / 0.1 \mathrm{CHI}$ and $0.25 \mathrm{Ag} /$ PVA/0.5CHI both releasing around $20 \%$ of silver, whereas the hydrogels with higher AgNP content (3.9Ag/ $\mathrm{PVA} / 0.1 \mathrm{CHI}$ and 3.9Ag/PVA/0.5CHI) exhibited faster release, with $43 \%$ and $36 \%$ of silver released after 48 hours, respectively. ${ }^{36}$ The slower initial burst release is favorable, as mentioned above, as it alleviates the danger of cytotoxicity, while allowing for higher amount of antibacterial agent to be released in the later period, thus maintaining the dressing sterility for a longer time.

Similarly to swelling properties, the diffusion coefficients of Ag through the hydrogel matrix $\left(D_{\mathrm{Ag}}\right)$ are a good indication of the release behavior. Release profiles could be fitted with many different mathematical models in order to evaluate the kinetics of silver release and to calculate these diffusion coefficients. Among the most widely-used models are early-time approximation (ETA), ${ }^{145}$ Korsmeyer-Peppas, ${ }^{150,151}$ Kopcha, ${ }^{152}$ and Makoid-Banakar, ${ }^{144,153}$ as well as by the well-known kinetic models (zero-, first-, second-order, etc.) ${ }^{127,154}$ that can help elucidate the kinetics of release. An overview of the most frequently-used models of silver release from different polymer carriers is provided in Table 5. The silver release from different hydrogels was generally found to comply with Fick's law of diffusion, ${ }^{31,34,35,130}$ and the $D_{\mathrm{Ag}}$ data for different systems are presented in Table 6 . Data represent release at $37^{\circ} \mathrm{C}$, in a physiological buffer. From the presented data, it could be observed that $D_{\mathrm{Ag}}$ values were quite similar among different hydrogels, with the orders of magnitude between $10^{-8}$ and $10^{-10} \mathrm{~cm}^{2} \mathrm{~s}^{-1}$. Ag/PVP hydrogels exhibited slightly lower diffusion coefficient $\left(1.64 \times 10^{-10} \mathrm{~cm}^{2} \mathrm{~s}^{-1}\right){ }^{130}$ compared to other samples. The influence of chitosan was evident, as chitosan-containing hydrogels exhibited lower $D_{\mathrm{Ag}}$ (Table 6) compared to Ag/PVA/Gr $\left(10.9 \times 10^{-8} \mathrm{~cm}^{2} \mathrm{~s}^{-131}\right)$. Further, $D_{\mathrm{Ag}}$ was smaller with increased chitosan content $\left(1.22 \times 10^{-9} \mathrm{~cm}^{2} \mathrm{~s}^{-1}\right.$ for $0.25 \mathrm{Ag} / \mathrm{PVA} / 0.5 \mathrm{CHI} / \mathrm{Gr}$, compared to $3.63 \times 10^{-9} \mathrm{~cm}^{2} \mathrm{~s}^{-1}$ for $0.25 \mathrm{Ag} / \mathrm{PVA} / 0.1 \mathrm{CHI} /$ 

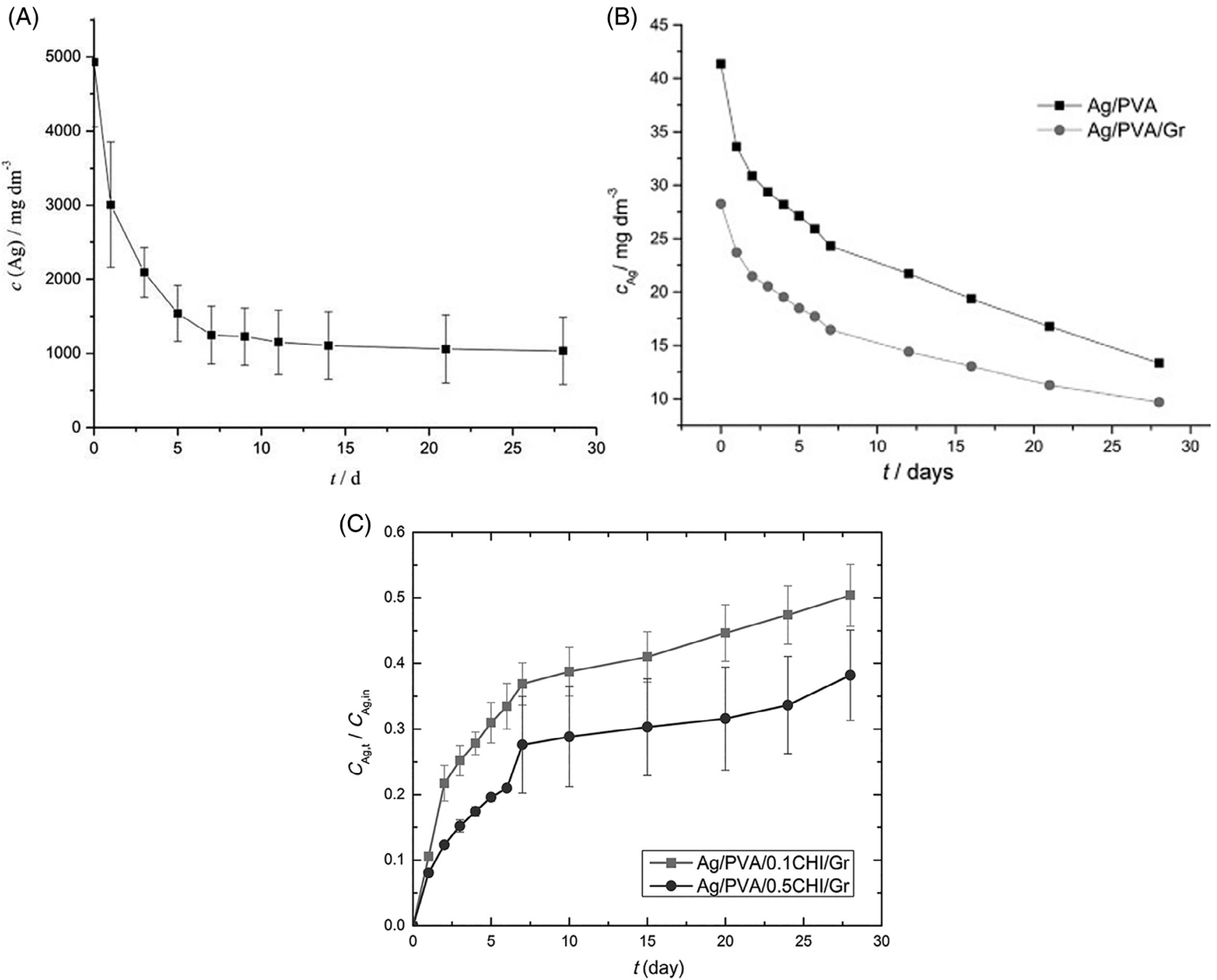

F I G U R E 8 Representative silver release profiles for A, Ag/PVP (reprinted with permission from Reference 130 (c)2014 Wiley), B, $\mathrm{Ag} / \mathrm{PVA}$ and Ag/PVA/Gr (Reprinted with permission from Reference 31 (2016 Elsevier), and C, Ag/PVA/CHI/Gr hydrogels (Reprinted with permission from Reference 34 (C2019 Elsevier)

$\mathrm{Gr}^{34}$ and $0.723 \times 10^{-8} \mathrm{~cm}^{2} \mathrm{~s}^{-1}$ for $3.9 \mathrm{Ag} / \mathrm{PVA} / 0.5 \mathrm{CHI} / \mathrm{Gr}$, compared to $8.41 \times 10^{-8} \mathrm{~cm}^{2} \mathrm{~s}^{-1}$ for $3.9 \mathrm{Ag} / \mathrm{PVA} / 0.1 \mathrm{CHI} /$ $\mathrm{Gr}^{35}$ ). This confirmed improved stabilization of AgNPs by interaction with chitosan macromolecules in the hydrogel.

The release behavior of different AgNP-loaded materials is likely to also be influenced by the properties of silver nanoparticles themselves, such as their sizes, size distributions, and distributions along the polymer matrices, as well as their shape and morphology. It has been established that size and shape of AgNPs directly affect their silver ion release kinetics, that is, oxidative dissolution in aqueous media-smaller nanoparticles with higher surface areas and therefore more reactive surfaces undergo faster dissolution. ${ }^{155}$ However, it was also established that many AgNPs properties could be tailored and controlled by the means of interactions with polymer matrix, ${ }^{156}$ that is, through selecting different polymers as carriers, as the polymer matrix can play a significant role in release kinetics. ${ }^{157}$ This is clearly also the case with electrochemically synthesized AgNPs, as can be observed from Table 6-the lowest Ag release diffusion coefficient was observed for PVP-based hydrogels, followed by chitosan containing ones, and $D_{\mathrm{Ag}}$ values were the highest for pure PVA-based (Ag/PVA and Ag/PVA/Gr) hydrogels. This can be explained by the interactions of AgNPs with different macromolecules in the polymer matrix, that is, the strongest interactions were achieved with PVP (which is a known AgNPs capping agent), whereas PVA alone is the weakest AgNP stabilizer. The interactions with chitosan could be used to tailor the release behavior, as the hydrogels with more $\mathrm{CHI}$ 
(ie, $0.5 \mathrm{wt} \%$ ) exhibited slower release and lower slope of the burst release period (Tables 4 and 6 and Figure 8) -allowing for longer overall sustained release. The effect of the interactions between the nanoparticles and the polymer matrices could also be examined on the example of chitosan-containing hydrogels. TEM examination of

T A B L E 4 Percentage of released silver after 48 hours from different hydrogels

\begin{tabular}{|c|c|c|}
\hline Sample & $\begin{array}{l}\text { Released } \\
\text { Ag }(\%)\end{array}$ & References \\
\hline $\mathrm{Ag} /$ alginate microbeads & $\approx 40-50$ & {$[28]$} \\
\hline $\mathrm{Ag} / \mathrm{PVP}$ & $\approx 50$ & [130] \\
\hline Ag/PVA galvanostatic & $\approx 16$ & [29] \\
\hline Ag/PVA/Gr galvanostatic & $\approx 19$ & [29] \\
\hline $\begin{array}{l}0.25 \mathrm{Ag} / \mathrm{PVA} \\
\text { constant-voltage }\end{array}$ & 26 & [31] \\
\hline $\begin{array}{l}0.25 \mathrm{Ag} / \mathrm{PVA} / \mathrm{Gr} \\
\text { constant-voltage }\end{array}$ & 25 & [31] \\
\hline 1.0Ag/PVA constant-voltage & 48 & {$[30]$} \\
\hline $\begin{array}{l}\text { 1.0Ag/PVA/Gr } \\
\text { constant-voltage }\end{array}$ & 63 & {$[30]$} \\
\hline $0.25 \mathrm{Ag} / \mathrm{PVA} / 0.1 \mathrm{CHI}$ & $\approx 19$ & [36] \\
\hline $0.25 \mathrm{Ag} / \mathrm{PVA} / 0.5 \mathrm{CHI}$ & $\approx 20$ & {$[36]$} \\
\hline 3.9Ag/PVA/0.1CHI & $\approx 43$ & {$[36]$} \\
\hline 3.9Ag/PVA/0.5CHI & $\approx 36$ & {$[36]$} \\
\hline $0.25 \mathrm{Ag} / \mathrm{PVA} / 0.1 \mathrm{CHI} / \mathrm{Gr}$ & $\approx 22$ & [34] \\
\hline $0.25 \mathrm{Ag} / \mathrm{PVA} / 0.5 \mathrm{CHI} / \mathrm{Gr}$ & $\approx 12$ & [34] \\
\hline 3.9Ag/PVA/0.1CHI/Gr & $\approx 60$ & {$[35]$} \\
\hline 3.9Ag/PVA/0.5CHI/Gr & $\approx 28$ & {$[35]$} \\
\hline
\end{tabular}

AgNPs inside 3.9Ag/PVA/0.1CHI and 3.9Ag/ PVA/0.5CHI hydrogels revealed that the AgNPs were more defected with rough surfaces and edges in the latter sample, that is, the one with higher CHI content. ${ }^{36}$ It could be expected that these nanoparticles would undergo faster dissolution and faster release, due to surface reactivity, as other research indicated. ${ }^{155}$ However, this did not happen and the release was clearly slower from $0.5 \mathrm{wt} \% \mathrm{CHI}$-containing hydrogels, as illustrated in Tables 4 and 6, and this could be explained by stronger interactions of AgNPs with the greater number of $-\mathrm{OH}$ and $-\mathrm{NH}_{2}$ groups on chitosan chains, leading to their better stabilization in hydrogels with more chitosan. These results clearly underline the potential of chitosan to tailor hydrogel-based wound dressings with silver nanoparticles.

T A B L E 6 Diffusion coefficients of silver during release from different hydrogels

\begin{tabular}{|lll|} 
Sample & $\boldsymbol{D}_{\text {Ag }}\left(\mathbf{c m}^{\mathbf{2}} \mathbf{s}^{-\mathbf{1}}\right)$ & References \\
\hline $\mathrm{Ag} / \mathrm{PVP}$ & $1.64 \times 10^{-10}$ & {$[22]$} \\
$\mathrm{Ag} / \mathrm{PVA}$ & $6.79 \times 10^{-8}$ & {$[30]$} \\
$\mathrm{Ag} / \mathrm{PVA} / \mathrm{Gr}$ & $10.9 \times 10^{-8}$ & {$[30]$} \\
$0.25 \mathrm{Ag} / \mathrm{PVA} / 0.1 \mathrm{CHI}$ & $2.85 \times 10^{-9}$ & {$[36]$} \\
\hline $0.25 \mathrm{Ag} / \mathrm{PVA} / 0.5 \mathrm{CHI}$ & $3.94 \times 10^{-9}$ & {$[36]$} \\
\hline $3.9 \mathrm{Ag} / \mathrm{PVA} / 0.1 \mathrm{CHI}$ & $1.43 \times 10^{-8}$ & {$[36]$} \\
\hline $3.9 \mathrm{Ag} / \mathrm{PVA} / 0.5 \mathrm{CHI}$ & $1.14 \times 10^{-8}$ & {$[36]$} \\
\hline $0.25 \mathrm{Ag} / \mathrm{PVA} / 0.1 \mathrm{CHI} / \mathrm{Gr}$ & $3.63 \times 10^{-9}$ & {$[34]$} \\
\hline $0.25 \mathrm{Ag} / \mathrm{PVA} / 0.5 \mathrm{CHI} / \mathrm{Gr}$ & $1.22 \times 10^{-9}$ & {$[34]$} \\
\hline $3.9 \mathrm{Ag} / \mathrm{PVA} / 0.1 \mathrm{CHI} / \mathrm{Gr}$ & $8.41 \times 10^{-8}$ & {$[35]$} \\
\hline $3.9 \mathrm{Ag} / \mathrm{PVA} / 0.5 \mathrm{CHI} / \mathrm{Gr}$ & $0.723 \times 10^{-8}$ & {$[35]$} \\
\hline
\end{tabular}

T A B L E 5 An overview of the most frequently used models for fitting of silver release and calculation of AgNPs diffusion coefficients

\begin{tabular}{|c|c|c|c|}
\hline $\begin{array}{l}\text { Name of the } \\
\text { model }\end{array}$ & Equation & Range of use & References \\
\hline Standard ETA & $\frac{C_{\mathrm{Ag}, \mathrm{t}}}{C_{\mathrm{Ag}, \mathrm{in}}}=4\left(\frac{D_{\mathrm{ETA}} t}{\pi \delta^{2}}\right)^{1 / 2}$ & $<60 \%$ release & {$[30,130,144,145]$} \\
\hline Modified ETA & $\begin{array}{l}\frac{C_{\mathrm{Ag}, \mathrm{t}}}{C_{\mathrm{Ag}, \mathrm{in}}}=4\left(\frac{D_{\mathrm{Ag}} t}{\pi r^{2}}\right)^{\frac{1}{2}}-\pi\left(\frac{D_{\mathrm{Ag}} t}{\pi r^{2}}\right)-\frac{\pi}{3}\left(\frac{D_{\mathrm{Ag}} t}{\pi r^{2}}\right)^{\frac{3}{2}} \\
+4\left(\frac{D_{\mathrm{Ag}} t}{\pi \delta^{2}}\right)^{\frac{1}{2}}-\frac{2 r}{\delta}\left[8\left(\frac{D_{\mathrm{Ag}} t}{\pi r^{2}}\right)-2 \pi\left(\frac{D_{\mathrm{Ag}} t}{\pi r^{2}}\right)^{3 / 2}-\frac{2 \pi}{3}\left(\frac{D_{\mathrm{Ag}} t}{\pi r^{2}}\right)^{2}\right]\end{array}$ & Up to $80 \%$ to $90 \%$ release & {$[35,36,145]$} \\
\hline Korsmeyer-Peppas & $\frac{C_{\mathrm{Ag}, \mathrm{t}}}{C_{\mathrm{Ag}, \mathrm{in}}}=k_{\mathrm{KP}} \cdot t^{\mathrm{n}}$ & $<60 \%$ release & {$[34-36,144,150,151]$} \\
\hline Kopcha & $\frac{C_{\mathrm{Ag}, \mathrm{t}}}{C_{\mathrm{Ag}, \mathrm{in}}}=\mathrm{A} \cdot t^{1 / 2}+\mathrm{B} \cdot t$ & Entire range & $34-36,144,152]$ \\
\hline Makoid-Banakar & $\frac{C_{\mathrm{Ag}, \mathrm{t}}}{C_{\mathrm{Ag}, \mathrm{in}}}=k_{\mathrm{MB}} \cdot t^{\mathrm{n}} \cdot \exp (-\mathrm{c} \cdot t)$ & Entire range & {$[34-36,144,153]$} \\
\hline Zero-order & $c_{\mathrm{Ag}}=c_{\mathrm{Ag}, 0}-k_{0} \cdot t$ & $\begin{array}{l}\text { Depending on the } \\
\text { kinetics }\end{array}$ & {$[127]$} \\
\hline
\end{tabular}




\section{3 | Antibacterial properties}

Silver nanoparticles along with silver ions have been recognized for a long time as one of the strongest and broadspectrum antibacterial agents. The mechanism of AgNPs activity involves cytoplasmic membrane damage, disruption of DNA replication through binding to sulfur- and phosphorus-containing groups, inhibition of respiratory processes, as well as ROS generation, causing membrane damage and protein denaturation. ${ }^{16-18,158}$ The antibacterial efficiency of AgNP-containing wound dressing materials depends strongly on the type and form of the material, the dynamics of silver release, and interactions with bacterial cultures. ${ }^{137,158}$ Some of the proposed modes of action of AgNPs against bacterial cells are illustrated in Figure 9. ${ }^{158}$ Silver nanoparticles-containing wound dressings based on different polymers have been evaluated for antibacterial activity as one of the most important properties of such materials.

Two standard antibacterial tests which are most often used are disc-diffusion and spread-plate or test in suspension. Disc-diffusion test consists of an agar plate inoculated with bacteria, over which the samples, for example, hydrogel discs are placed, and the widths of inhibition zones are measured around the sample after incubation period (usually 24 hours). Similarly, test in suspension is conducted by incubating samples in the bacterial suspension (bacterial inoculum in a biological medium, usually phosphate buffer (PB) or Luria-Bertani (LB) broth); the aliquots of this suspension are sampled at predetermined periods, serially diluted and spread over an agar plate, after which the plates are incubated to grow bacterial colonies that are subsequently counted. This method provides quantitative data about bacterial viability, which is expressed in colony forming units per milliliter $\left(\mathrm{CFU} \mathrm{ml} \mathrm{m}^{-1}\right)$. There are many bacterial strains which could be used in these assays, but two most common are Gram-positive bacterium $S$ aureus-most frequent culprit for skin infections, ${ }^{159}$ and Gram-negative $E$ coli.

Antibacterial activity of $\mathrm{Ag} / \mathrm{Alg}$ microbeads, containing AgNPs concentration of $1.0 \mathrm{mM}$, was evaluated by test in suspension against $S$ aureus and $E$ coli. ${ }^{26,28}$ Both wet and dried microbeads caused reduction of bacterial colonies numbers by $\approx 1$ logarithmic unit after 1 hour of incubation, however, the bacteria continued to grow after 24 hours (although slower than the control), ${ }^{26,28}$ therefore their antibacterial activity could be characterized as only bacteriostatic. Similarly, antibacterial activity of $\mathrm{Ag} / \mathrm{Alg} / \mathrm{PVA}$ microbeads was evaluated against $E$ coli, ${ }^{120}$ and it was found that bacterial colonies count dropped from the initial $\approx 10^{6}$ by 2 and 3 logarithmic units after 1 and 24 hours, respectively, which confirmed their strong antibacterial potential. ${ }^{120}$ Further, the Ag/PVP hydrogels with constant-voltage synthesized AgNPs were evaluated for antibacterial effect by disc-diffusion assay, which indicated $1 \mathrm{~mm}$ inhibition zone around the hydrogel sample, confirming its good activity against $S$ aureus. ${ }^{130}$

Concerning Ag/PVA and Ag/PVA/Gr hydrogels, an effect of electrochemical synthesis route can be evaluated with respect to antibacterial properties, as one set of these samples were prepared by galvanostatic reduction in
FIG URE 9 Proposed antibacterial mechanisms of AgNPs through contact or entry inside a bacterial cell. Reprinted with permission from Reference 158 (C) 2018 Elsevier [Color figure can be viewed at wileyonlinelibrary.com]

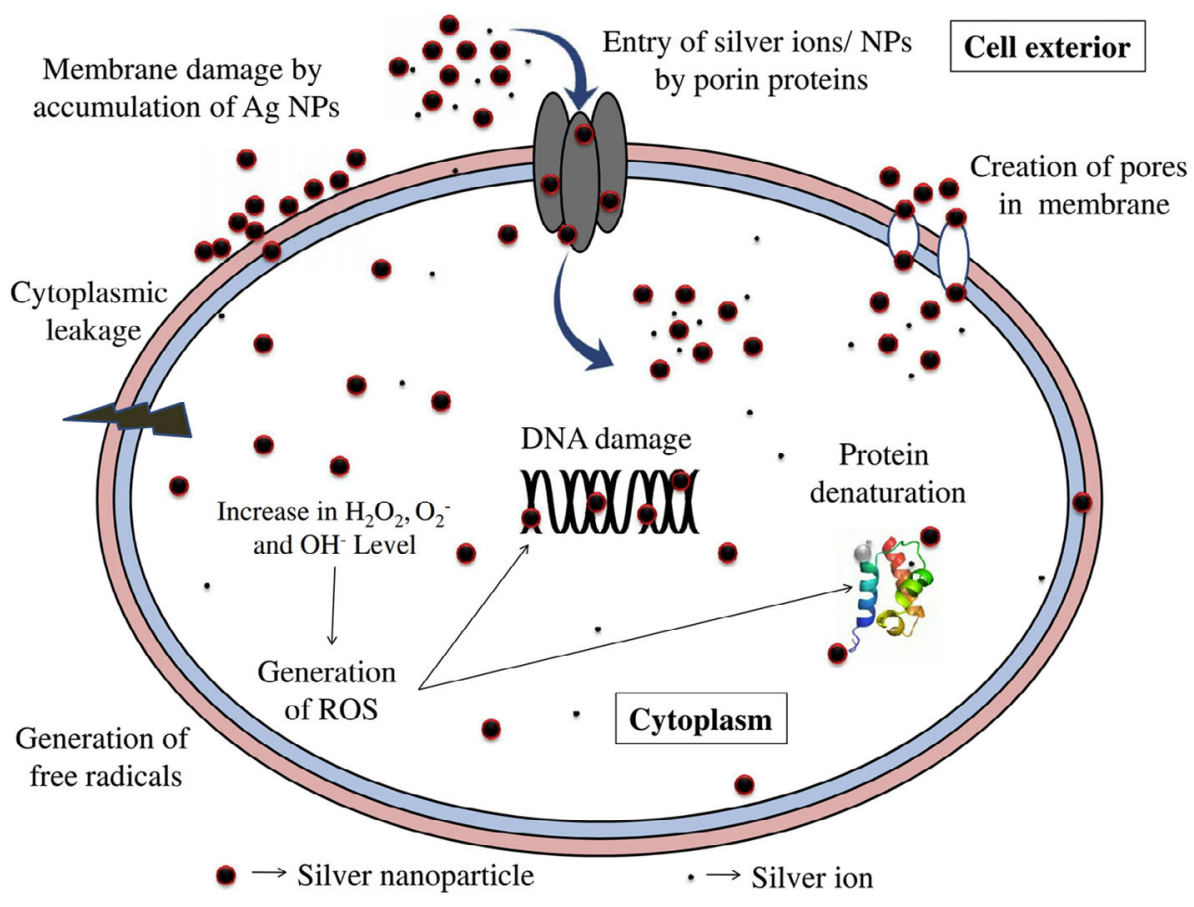


colloid followed by cross linking to obtain hydrogel, ${ }^{29}$ whereas the other samples were obtained by constantvoltage in situ reduction in hydrogel matrix. ${ }^{31}$ Galvanostatically obtained Ag/PVA caused visible reduction of E. coli and S. aureus already after 1 hour, whereas complete reduction of bacterial colonies occurred after 3 and 24 hours, respectively, for these two bacterial strains. ${ }^{29}$ Galvanostatic Ag/PVA/Gr hydrogel exhibited an even stronger effect, causing complete eradication of bacteria after 1 hour ( $S$ aureus) and after 3 hours (E coli). ${ }^{29}$ On the other hand, the constant-voltage synthesized Ag/PVA and Ag/PVA/Gr hydrogels caused complete destruction of $E$ coli after 1 hour, and $S$ aureus after 3 hours, ${ }^{31}$ indicating even stronger antibacterial effect of their galvanostatically-obtained counterparts.

Finally, the chitosan-containing hydrogels possessed by far the strongest antibacterial activities. The $0.25 \mathrm{Ag} /$ PVA/0.1CHI/Gr and 0.25Ag/PVA/0.5CHI/Gr hydrogels exhibited almost immediate destructive effect, causing $100 \%$ reduction of bacterial viability after only 1 hour, and causing visible decrease in colony counts $(\approx 1-2 \log$ units) even after 15 minutes, against both $E$ coli and $S$ aureus. ${ }^{35}$ Similar effects were observed by disc-diffusion assay, with wide inhibition zones around both samples. $^{34}$ More interestingly, even hydrogels without AgNPs, that is, especially PVA/0.5CHI and PVA/0.5CHI/Gr, exhibited antibacterial activity, which was more pronounced against $S$ aureus, causing $100 \%$ reduction of this bacterium after 1 hour. ${ }^{35,36}$ This effect is not entirely unexpected, as chitosan is well known for its intrinsic antibacterial properties ${ }^{74}$; however it contributed to significant synergistic effect of AgNPs and CHI. ${ }^{34-36}$

The size-dependent antibacterial activity is a wellknown property of silver nanoparticles. ${ }^{137,138}$ It was particularly shown that smaller nanoparticles (eg, with diameter less than $10 \mathrm{~nm}$ ) exhibited much stronger antibacterial activity than the larger ones. ${ }^{136}$ With this in mind, the antibacterial efficacy of different wound dressing materials could be compared with regard to silver nanoparticles sizes. As discussed above, the TEM-derived size distributions of galvanostatically synthesized AgNPs in $\mathrm{Ag} / \mathrm{PVA}$ and $\mathrm{Ag} / \mathrm{PVA} / \mathrm{Gr}$ colloid were found to be in the range 10 to $40 \mathrm{~nm} .^{29}$ These $\mathrm{Ag} / \mathrm{PVA}$ and $\mathrm{Ag} / \mathrm{PVA} / \mathrm{Gr}$ dressings (with $3.9 \mathrm{mM}$ AgNPs loading) generally caused complete destruction of $S$ aureus and $E$ coli bacteria after 3 hours. ${ }^{29}$ On the other hand, the AgNPs (1.0 mM loading) in $\mathrm{Ag} / \mathrm{Alg}$ colloids and microbeads were spherical and sized 10 to $30 \mathrm{~nm},{ }^{26}$ and this translated to reduction of $S$. aureus and $E$. coli colonies by $\approx 1$ logarithmic unit after 1 hour incubation, after which the bacteria continued to grow up to 24 hours, ${ }^{26,28}$ Obviously, the larger nanoparticles exhibit a certain antibacterial effect but much more efficient are those AgNPs smaller than $10 \mathrm{~nm}$, as shown on the example of chitosan-containing hydrogels (ie, Ag/PVA/0.1CHI, Ag/PVA/0.5CHI, Ag/PVA/0.1CHI/Gr, and Ag/PVA/0.5CHI/Gr). ${ }^{35,36}$ These hydrogels caused $100 \%$ reduction in bacterial cell numbers after only 1 hour, and with much lower AgNP loadings $(0.25 \mathrm{mM}),{ }^{35,36}$ compared to the other formulations, that is, those without $\mathrm{CHI}$ that were discussed above. This could be related to the very small AgNPs sizes $(<10 \mathrm{~nm}$, as determined by both TEM and DLS); however it could also be ascribed to the specific surface morphology of AgNPs in these hydrogels, as they were found to be cuboctahedral, that is, generally sphere-shaped, but with many surface irregularities and rough edges, especially those in hydrogels with higher CHI content ( $0.5 \mathrm{wt}$ $\%) .^{36}$ Surface defects (eg, edges, corners, surface charges) have been shown to influence metal oxide nanoparticles antibacterial activity, ${ }^{160}$ mainly as they facilitate the ROS generation, ${ }^{161}$ which has been highlighted as one of the mechanisms of AgNPs antibacterial activity. ${ }^{162}$ Thus, the presence of chitosan could affect not only size, but also morphology that could contribute to the formation of more active AgNPs. All of these results indicated that PVA and CHI-based hydrogels possess particularly strong potential for wound dressing applications.

\section{4 | Cytotoxicity}

Biocompatibility and nontoxicity is the imperative when designing new wound dressing materials. Silver nanoparticles and/or silver ions are known to be potentially toxic toward not only bacteria, but also healthy, live cells. ${ }^{137,163}$ Aside from dose-dependent AgNP cytotoxicity mechanisms that are similar to their mode of antibacterial action, ${ }^{137}$ a major concern is also accumulation of AgNPs and/or the $\mathrm{Ag}^{+}$ions that they release through oxidative dissolution, giving rise to potential time-dependent or accumulated-dose toxicity. ${ }^{137,164}$ Further, another toxicity concern could be the AgNPs sizedependent cytotoxicity, ${ }^{165-168}$ which must be taken into account, especially considering that smaller AgNPs also exhibit the best antibacterial properties, as discussed above. It has also been shown that the AgNPs with irregular surfaces and surface defects could induce stronger cytotoxicity toward fish gill cells NPs, ${ }^{169}$ so the surface morphology of AgNPs could also be one of the factors to consider when evaluating AgNP-loaded wound dressings. Therefore, it is important to confirm nontoxicity of AgNP-containing materials toward model cell lines, before they could be considered for biomedical applications. Selected results of cytotoxicity studies for different polymer materials with AgNPs are presented in Table 7, 
and the cell lines used for assays are indicated for comparison.

MTT assay is a standard colorimetric test used to evaluate cytotoxicity of materials. The assay is based on 3-(4,5-dimethylthiazol-2-yl)-2,5-diphenyl tetrazolium bromide salt (MTT), which is reduced to insoluble formazan due to mitochondrial activity of viable cells, changing the color to purple. ${ }^{170}$ Thus, the viability of the cells after incubation with samples can be estimated by measuring the intensity of the solution absorbance.

The cytotoxicity of $\mathrm{Ag} / \mathrm{Alg}$ microbeads toward bovine calf chondrocytes was evaluated by MTT test in monolayer cultures, as well as in 3D cultures in perfusion bioreactors. ${ }^{28}$ In order to evaluate dose-dependence of AgNPs cytotoxicity, the amount of released silver was measured in parallel with monolayer studies. The results indicated that the cell survival was higher than $90 \%$ in the presence of AgNP concentrations up to $5 \mu \mathrm{g} \mathrm{ml}^{-1}$, whereas higher concentrations caused significant cytotoxic effect. ${ }^{28}$ However, under perfusion bioreactor conditions imitating in vivo environment, even concentrations of AgNPs that were cytotoxic in monolayer cultures had negligible effect on the cells viability in 3D cultures, ${ }^{28}$ which indicated the importance of more comprehensive studies to evaluate the biocompatibility of a material. These results also indicated that a material, which does not exhibit cytotoxicity in monolayer in vitro cultures, could be considered safe, as the cells are more sensitive in these conditions. However, and especially with silver, it is advisable to opt for the lowest possible concentration which provides satisfactory antibacterial effect and does not cause any toxicity.

Poly(vinyl alcohol)-based hydrogels, namely, PVA, $\mathrm{PVA} / \mathrm{Gr},{ }^{122} \mathrm{Ag} / \mathrm{PVA}$, and $\mathrm{Ag} / \mathrm{PVA} / \mathrm{Gr}^{31}$ were subjected to MTT cytotoxicity assay with peripheral blood mononuclear cells (PBMC) chosen as a model cell line that is the first line of defense of the organism's immune system. ${ }^{31}$ PBMC cells exhibited high survival rates $(>80 \%)$ in the presence of hydrogels without silver (Table 7). ${ }^{122}$ Silver nanoparticles were synthesized at constant voltage in hydrogels preswollen in $\mathrm{AgNO}_{3}$ solutions of different concentrations $(0.25,0.5,1.0$, and $3.9 \mathrm{mM})$ in order to establish the dose-dependence of AgNPs cytotoxicity. ${ }^{31}$ The obtained results indicated severe cytotoxicity of hydrogels with higher AgNPs concentrations-1.0 and $3.9 \mathrm{mM}$ (viability lower than $40 \%$ and $20 \%$, respectively). The hydrogels with $0.5 \mathrm{mM}$ AgNPs exhibited mild cytotoxicity ( $\approx 60 \%$ viability), whereas only the lowest concentration $(0.25 \mathrm{mM})$ was proved nontoxic $(>80 \%$ viability). ${ }^{31}$ Those results clearly illustrated the dependence of AgNPs cytotoxicity on their concentration.

MTT assay for chitosan-based hydrogels was performed on two model fibroblast cell lines-a mice (L929) and a human one (MRC-5) ${ }^{34}$ Mainly the hydrogels with lowest AgNP concentration were tested, as they were proved earlier to be noncytotoxic, ${ }^{31}$ however, the cytotoxic effect of 3.9Ag/PVA/0.1CHI and 3.9Ag/PVA/0.5CHI hydrogels (obtained from $3.9 \mathrm{mM} \mathrm{Ag}^{+}$swelling solution)

T A B L E 7 Cell viability in the presence of different hydrogels with AgNPs, determined by MTT cytotoxicity test

\begin{tabular}{|llll}
\hline Sample & Cell line & Cell viability (\%) & References \\
\hline Ag/Alg microbeads & Bovine calf chondrocytes & $>90$ & {$[28]$} \\
\hline PVA hydrogel & PBMC & $85.9 \pm 1.6$ & {$[122]$} \\
\hline PVA/Gr hydrogel & PBMC & $81.8 \pm 6.6$ & {$[122]$} \\
\hline $0.25 \mathrm{Ag} / \mathrm{PVA}$ (constant-voltage) & PBMC & $82.5 \pm 5.4$ & {$[31]$} \\
\hline $0.25 \mathrm{Ag} / \mathrm{PVA} / \mathrm{Gr}$ (constant-voltage) & PBMC & $69.4 \pm 15.3$ & {$[31]$} \\
\hline $0.25 \mathrm{Ag} / \mathrm{PVA} / 0.1 \mathrm{CHI}$ & MRC-5 & $98.2 \pm 0.50$ & {$[36]$} \\
\hline $0.25 \mathrm{Ag} / \mathrm{PVA} / 0.5 \mathrm{CHI}$ & MRC-5 & $92.7 \pm 1.3$ & {$[36]$} \\
\hline $0.25 \mathrm{Ag} / \mathrm{PVA} / 0.1 \mathrm{CHI}$ & L929 & $105 \pm 0.75$ & {$[36]$} \\
\hline $0.25 \mathrm{Ag} / \mathrm{PVA} / 0.5 \mathrm{CHI}$ & L929 & $110 \pm 1.4$ & {$[36]$} \\
\hline $3.9 \mathrm{Ag} / \mathrm{PVA} / 0.1 \mathrm{CHI}$ & MRC-5 & $97.0 \pm 2.3$ & {$[36]$} \\
\hline $3.9 \mathrm{Ag} / \mathrm{PVA} / 0.5 \mathrm{CHI}$ & MRC-5 & $96.8 \pm 2.6$ & {$[36]$} \\
\hline $3.9 \mathrm{Ag} / \mathrm{PVA} / 0.1 \mathrm{CHI}$ & L929 & $104 \pm 0.43$ & {$[36]$} \\
\hline $3.9 \mathrm{Ag} / \mathrm{PVA} / 0.5 \mathrm{CHI}$ & L929 & $105 \pm 2.6$ & {$[36]$} \\
\hline $0.25 \mathrm{Ag} / \mathrm{PVA} / 0.1 \mathrm{CHI} / \mathrm{Gr}$ & MRC-5 & $111 \pm 5.7$ & {$[34]$} \\
\hline $0.25 \mathrm{Ag} / \mathrm{PVA} / 0.5 \mathrm{CHI} / \mathrm{Gr}$ & MRC-5 & $95.4 \pm 2.8$ & {$[34]$} \\
\hline $0.25 \mathrm{Ag} / \mathrm{PVA} / 0.1 \mathrm{CHI} / \mathrm{Gr}$ & L929 & $72.0 \pm 2.6$ & {$[34]$} \\
\hline $0.25 \mathrm{Ag} / \mathrm{PVA} / 0.5 \mathrm{CHI} / \mathrm{Gr}$ & L929 & $68.9 \pm 2.1$ & {$[34]$} \\
\hline
\end{tabular}


was also evaluated in order to confirm the safety of all materials. ${ }^{36}$ The viability of the MRC- 5 cells was $>90 \%$ in the presence of hydrogels both with and without AgNPs (Table 7), and even higher than 100\% (indicating active proliferation and growth) in some cases-even in those hydrogels with higher AgNP content. ${ }^{34,36}$ The L929 cell line however exhibited slightly higher sensitivity, but the cells were still sufficiently viable to consider the hydrogels nontoxic and safe for biomedical applications. ${ }^{34}$

As discussed above, all of the different wound dressing materials with electrochemically synthesized AgNPs exhibited satisfactory biocompatibility and nontoxicity toward different model cell lines and could be considered safe for biomedical use. Some of the concerns raised could relate to size-dependent toxicity of AgNPs, ${ }^{165-168}$ as well as their accumulated-dose ${ }^{137,164}$ and shape and morphology-related ${ }^{169}$ cytotoxicity; however, these risks could be curbed through controlling the loading of AgNPs as shown on the example of Ag/PVA/0.1CHI and $\mathrm{Ag} / \mathrm{PVA} / 0.5 \mathrm{CHI}$ hydrogels, which contained small AgNPs with irregular surfaces that contributed to their potent antibacterial effect, but the materials were nontoxic and possessed excellent biocompatibility due to the smaller doses applied. ${ }^{36}$ All of these results underline the importance of tailoring many different aspects of AgNPs in wound dressings, including their size, distribution, shape, and loading or dose (that electrochemical synthesis methods certainly allow to great extent), as well as the significance of testing the biocompatibility of these materials, not only in vitro, but also in vivo.

\section{5 | CHITOSAN-BASED HYDROGELS WITH AgNPS AS PROMISING WOUND DRESSING MATERIALS}

From the discussion and literature overview presented in the previous sections, it could be noticed that hydrogels containing chitosan exhibited arguably the best properties. PVA/CHI hydrogels were shown to provide excellent stabilization to AgNPs, enabling the formation of nanoparticles as small as 5 to $10 \mathrm{~nm}$, as confirmed by TEM analysis (Figure 5). The slower release of AgNPs from PVA/CHI hydrogels with increased chitosan content $^{34}$ also pointed to their strong interactions with polymer matrices that enabled improved stabilization (Table 4). What is more, Raman spectroscopy has confirmed that the stabilization of AgNPs is achieved via interactions with free hydroxyl groups on the polymer chain, due to the appearance of a band at low wavenumbers $\left(\approx 230 \mathrm{~cm}^{-1}\right)$, originating from $\mathrm{Ag}-\mathrm{O}$ bond vibrations. ${ }^{34} \mathrm{CHI}$ has also been shown to increase the yield of electrochemical synthesis, allowing obtaining higher AgNP concentration under the same experimental conditions. ${ }^{33}$ Additionally, the increased chitosan content improved sorption properties and caused higher swelling degree of both PVA/CHI/Gr and Ag/PVA/CHI/Gr hydrogels. ${ }^{35}$ Strong synergistic antibacterial effect of chitosan and AgNPs has also been confirmed by both discdiffusion assay and test in suspension, ${ }^{34,35}$ confirming that intrinsic antibacterial properties of $\mathrm{CHI}$ were retained in blend with PVA. Despite indications in the literature that chitosan may induce some cytotoxic effect in fibroblast cell lines, ${ }^{171}$ the chitosan and AgNPscontaining hydrogels were proved to be noncytotoxic ${ }^{34,36}$ and therefore these materials can be considered as a viable solution for next-generation wound dressings.

Taking into account the presented results and comparisons, it could be concluded that hydrogels containing chitosan could be the best option for further research in this area of biomaterials science.

\section{6 | CONCLUSIONS}

In this article, we have reviewed the polymer-based hydrogels and films with electrochemically incorporated silver nanoparticles, aimed for applications as wound dressing materials. Two different routes for electrochemical AgNPs synthesis were overviewed; the first method dealt with galvanostatic synthesis of AgNPs in colloid solutions, while the second was in situ silver nanoparticles synthesis directly inside the hydrogel matrix, previously swollen in $\mathrm{Ag}^{+}$ions precursor solutions. The reviewed materials were based on different polymers, that is, alginate, chitosan, poly(vinyl alcohol), and poly(vinyl pyrrolidone), and were prepared in different forms, such as microbeads, hydrogels, films, and microfibers.

It was shown that the electrochemical synthesis was performed successfully in all these materials, and the concentrations, sizes and properties of the obtained AgNPs were compared among different materials on the basis of UV-visible spectroscopy and transmission electron microscopy results. Further, the sorption characteristics and silver release profiles were compared among different AgNPs-containing hydrogels. All materials also exhibited varying antibacterial activity against $S$ aureus and $E$ coli bacterial strains, while chitosan-containing hydrogels exhibited the strongest antibacterial effect and synergistic CHI-AgNPs action. MTT assay was shown to have confirmed the noncytotoxicity of different materials toward such cell lines as bovine calf chondrocytes, PBMCs, as well as MRC-5 and L929 fibroblasts. Poly(vinyl alcohol)/chitosan-based hydrogels with 
electrochemically incorporated AgNPs have demonstrated the best physicochemical and biological properties, and therefore have presented themselves as strong prospective candidates for further wound dressing materials research. Potential shortcomings of electrochemical AgNPs syntheses were mainly identified as costs around process scale-up, so it is recommended that further research directions be focused precisely on this area.

\section{ACKNOWLEDGMENTS}

The authors wish to thank all co-workers who contributed with their work to obtain the experimental results presented in this review. Their names can be seen in our joint articles listed in the references. This work was supported by the Ministry of Education, Science and Technological Development of the Republic of Serbia (Contract No. 451-03-68/2020-14/200135 and 451-03-68/2020-14/200287).

\section{ORCID}

Vesna Mišković-Stanković @i] https://orcid.org/0000-00016525-9820

\section{REFERENCES}

[1] T. S. Stashak, E. Farstvedt, A. Othic, Clin. Tech. Equine Pract. 2004, 3, 148. https://doi.org/10.1053/j.ctep.2004.08.006.

[2] J. M. A. Blair, M. A. Webber, A. J. Baylay, D. O. Ogbolu, L. J. V. Piddock, Nat. Rev. Microbiol 2015, 13(42), 42. https:// doi.org/10.1038/nrmicro3380.

[3] E. Caló, V. V. Khutoryanskiy, Eur. Polym. J. 2015, 65, 252. https://doi.org/10.1016/j.eurpolymj.2014.11.024.

[4] J. Sun, H. Tan, Materials 2013, 6, 1285. https://doi.org/10. 3390/ma6041285.

[5] F. R. Diniz, R. C. A. P. Maia, L. Rannier, L. N. Andrade, M. V. Chaud, C. F. da Silva, C. B. Corrêa, R. L. C. de Albuquerque Junior, L. P. da Costa, S. R. Shin, S. Hassan, E. Sanchez-Lopez, E. B. Souto, P. Severino, Nanomaterials 2020, 10, 390. https://doi.org/10.3390/nano10020390.

[6] A. Hebeish, M. Hashem, M. M. A. El-Hady, S. Sharaf, Carbohydr. Polym. 2013, 92, 407. https://doi.org/10.1016/j. carbpol.2012.08.094.

[7] R. Jayakumar, M. Prabaharan, P. T. Sudheesh Kumar, S. V. Nair, H. Tamura, Biotechnol. Adv. 2011, 29, 322. https:// doi.org/10.1016/j.biotechadv.2011.01.005.

[8] S. Bhowmick, V. Koul, Mater. Sci. Eng. C 2016, 59, 109. https://doi.org/10.1016/j.msec.2015.10.003.

[9] K. H. Hong, Polym. Eng. Sci. 2007, 47, 43. https://doi.org/10. 1002/pen20660.

[10] Ž. Jovanović, A. Krklješ, J. Stojkovska, S. Tomić, B. Obradović, V. Mišković-Stanković, Z. Kacarevic-Popovic, Radiat. Phys. Chem. 2011, 80, 1208. https://doi.org/10.1016/j. radphyschem.2011.06.005.

[11] S. Torres-Giner, R. Perez-Masia, J. M. Lagaron, Polym. Eng. Sci. 2016, 56, 500. https://doi.org/10.1002/pen24274.

[12] T. T. T. Nguyen, B. Tae, J. S. Park, J. Mater. Sci. 2011, 46, 6528. https://doi.org/10.1007/s10853-011-5599-0.
[13] A. Bal, F. E. Çepni, Ö. Çakir, I. Acar, G. Güçlü, Brazilian J. Chem. Eng. 2015, 32, 509. https://doi.org/10.1590/01046632.20150322s00003066.

[14] Y. Zhou, Q. Dong, H. Yang, X. Liu, X. Yin, Y. Tao, Z. Bai, W. Xu, Carbohydr. Polym. 2017, 168, 220. https://doi.org/10. 1016/j.carbpol.2017.03.044.

[15] D. Zhang, W. Zhou, B. Wei, X. Wang, R. Tang, J. Nie, J. Wang, Carbohydr. Polym. 2015, 125, 189. https://doi.org/10. 1016/j.carbpol.2015.02.034.

[16] M. Rai, A. Yadav, A. Gade, Biotechnol. Adv. 2009, 27, 76. https://doi.org/10.1016/j.biotechadv.2008.09.002.

[17] N. Duran, M. Duran, M. B. de Jesus, A. B. Seabra, W. J. Favaro, G. Nakazato, Nanomed.-Nanotechnol. 2016, 12, 789. https://doi.org/10.1016/j.nano.2015.11.016.

[18] Q. L. Feng, J. Wu, G. Q. Chen, F. Z. Cui, T. N. Kim, J. O. Kim, J. Biomed. Mater. Res. 2000, 52, 662. https://doi. org/10.1002/1097-4636(20001215)52:4<662::AID-JBM10>3.0. $\mathrm{CO} ; 2-3$.

[19] M. Konop, T. Damps, A. Misicka, L. Rudnicka, J. Nanomater. 2016, 2016, 7614753. https://doi.org/10.1155/2016/7614753.

[20] L. Dai, B. Nadeau, X. An, D. Cheng, Z. Long, Y. Ni, Sci. Rep. 2016, 6, 7. https://doi.org/10.1038/srep36497.

[21] Ž. Jovanović, A. Radosavljević, M. Šiljegović, N. Bibić, V. Mišković-Stanković, Z. Kačarević-Popovic, Radiat. Phys. Chem. 2012, 81, 1720. https://doi.org/10.1016/j.radphyschem. 2012.05.019.

[22] Ž. Jovanović, A. Radosavljević, Z. Kačarević-Popović, J. Stojkovska, A. Perić-Grujić, M. Ristić, I. Z. Matić, Z. D. Juranić, B. Obradovic, V. Mišković-Stankovic, Colloid. Surface. B 2013, 105, 230. https://doi.org/10.1016/j.colsurfb. 2012.12.055.

[23] J. Spasojevic, A. Radosavljevic, J. Krstic, M. Mitric, M. Popovic, Z. Rakocevic, M. Kalagasidis-Krusic, Z. Kacarevic-Popovic, Polym. Compos. 2017, 38, 1014. https:// doi.org/10.1002/pc.23665.

[24] L. Lu, A. Kobayashi, K. Tawa, Y. Ozaki, Chem. Mater. 2006, 18, 4894. https://doi.org/10.1021/cm0615875.

[25] S. R. Montoro, S. D. F. Medeiros, G. M. Alves, Nanostructured Polymer Blends, Elsevier Inc., Amsterdam, NL 2013, p. 325. https://doi.org/10.1016/B978-1-4557-3159-6.00010-9.

[26] Ž. Jovanović, J. Stojkovska, B. Obradović, V. MiskovicStankovic, Mater. Chem. Phys. 2012, 133, 182. https://doi.org/ 10.1016/j.matchemphys.2012.01.005.

[27] B. Obradović, V. Mišković-Stanković, Z. Jovanovic, J. Stojkovska Intelectual Property Office of the Republic of Serbia, RS Patent No. RS53508, 2015.

[28] J. Stojkovska, D. Kostić, Ž. Jovanović, M. VukašinovićSekulić, V. Mišković-Stanković, B. Obradović, Carbohydr. Polym. 2014, 111, 305. https://doi.org/10.1016/j.carbpol.2014. 04.063 .

[29] R. Surudžić, A. Janković, N. Bibić, M. Vukašinović-Sekulić, A. Perić-Grujić, V. Mišković-Stanković, S. J. Park, K. Y. Rhee, Compos. Part B Eng. 2016, 85, 102. https://doi.org/10.1016/j. compositesb.2015.09.029.

[30] M. M. Abudabbus, I. Jevremović, K. Nešović, A. Perić-Grujić, K. Y. Rhee, V. Mišković-Stanković, Compos. Part B Eng. 2018, 140, 99. https://doi.org/10.1016/j.compositesb.2017.12.017.

[31] M. M. Abudabbus, I. Jevremović, A. Janković, A. PerićGrujić, I. Matić, M. Vukašinović-Sekulić, D. Hui, K. Y. Rhee, 
V. Mišković-Stanković, Compos. Part B Eng. 2016, 104, 26 https://doi.org/10.1016/j.compositesb.2016.08.024.

[32] K. Nešović, M. M. Abudabbus, K. Y. Rhee, V. MiškovićStanković, Croat. Chem. Acta 2017, 90, 207. https://doi.org/ 10.5562/cca3133.

[33] K. Nešović, V. Kojić, K. Y. Rhee, V. Mišković-Stanković, Corrosion 2017, 73, 1437. https://doi.org/10.5006/2507.

[34] K. Nešović, A. Janković, V. Kojić, M. Vukašinović-Sekulić, A. Perić-Grujić, K. Y. Rhee, V. Mišković-Stanković, Compos Part B Eng. 2018, 154, 175. https://doi.org/10.1016/j. compositesb.2018.08.005.

[35] K. Nešović, A. Janković, A. Perić-Grujić, M. VukašinovićSekulić, T. Radetić, L. Živković, S. J. Park, K. Yop Rhee, V. Mišković-Stanković, J. Ind. Eng. Chem. 2019, 77, 83. https://doi.org/10.1016/j.jiec.2019.04.022.

[36] K. Nešović, A. Janković, T. Radetić, M. Vukašinović-Sekulić, V. Kojić, L. Živković, A. Perić-Grujić, K. Y. Rhee, V. Mišković-Stanković, Eur. Polym. J. 2019, 121, 109257. https://doi.org/10.1016/j.eurpolymj.2019.109257.

[37] J. Koehler, F. P. Brandl, A. M. Goepferich, Eur. Polym. J. 2018, 100, 1. https://doi.org/10.1016/j.eurpolymj.2017.12.046.

[38] J. S. Boateng, K. H. Matthews, H. N. E. Stevens, G. M. Eccleston, J. Pharm. Sci. 2008, 97, 2892. https://doi.org/10.1002/jps.

[39] K. C. Broussard, J. G. Powers, Am. J. Clin. Dermatol. 2013, 14, 449. https://doi.org/10.1007/s40257-013-0046-4.

[40] A. Bianchera, O. Catanzano, J. Boateng, L. Elviri, The Place of Biomaterials in Wound Healing. in Therapeutic Dressings Wound Healing Applications (Ed: J. Boateng), John Wiley and Sons Ltd, Hoboken, NJ 2020, p. 337. https://doi.org/10.1002/ 9781119433316.ch15.

[41] J. G. Powers, L. M. Morton, T. J. Phillips, Dermatol. Ther 2013, 26, 197. https://doi.org/10.1111/dth.12055.

[42] M. Naseri-Nosar, Z. M. Ziora, Carbohydr. Polym. 2018, 189 (379), 379. https://doi.org/10.1016/j.carbpol.2018.02.003.

[43] A. Gupta, S. M. Bri, S. Swingler, H. Gibson, V. Kannappan, G. Adamus, M. Kowalczuk, C. Martin, I. Radecka, Biomacromolecules, 2020, 21, 1802. https://doi.org/10.1021/acs. biomac.9b01724.

[44] R. Koivuniemi, T. Hakkarainen, J. Kiiskinen, M. Kosonen, J. Vuola, J. Valtonen, K. Luukko, H. Kavola, M. Yliperttula, Adv. Wound Care 2019, 9, 199. https://doi.org/10.1089/wound.2019.0982.

[45] X. Yang, W. Liu, G. Xi, M. Wang, B. Liang, Y. Shi, Y. Feng, X. Ren, C. Shi, Carbohydr. Polym. 2019, 222, 115012. https:// doi.org/10.1016/j.carbpol.2019.115012.

[46] R. Gharibi, S. Kazemi, H. Yeganeh, V. Tafakori, Int. J. Biol. Macromol. 2019, 131, 1044. https://doi.org/10.1016/j. ijbiomac.2019.03.185.

[47] R. Innocenti Malini, J. Lesage, C. Toncelli, G. Fortunato, R. M. Rossi, F. Spano, Eur. Polym. J. 2019, 110, 276. https:// doi.org/10.1016/j.eurpolymj.2018.11.017.

[48] M. A. Matica, F. L. Aachmann, A. Tøndervik, H. Sletta, V. Ostafe, Int. J. Mol. Sci. 2019, 20, 1. https://doi.org/10.3390/ ijms20235889.

[49] E. Kenawy, A. M. Omer, T. M. Tamer, M. A. Elmeligy, M. S. M. Eldin, Int. J. Biol. Macromol. 2019, 139, 440. https:// doi.org/10.1016/j.ijbiomac.2019.07.191.

[50] M. S. Rubina, E. E. Said-Galiev, A. V. Naumkin, A. V. Shulenina, O. A. Belyakova, A. Y. Vasil'kov, Polym. Eng. Sci. 2019, 59, 2479. https://doi.org/10.1002/pen.25122.
[51] J. Stojkovska, Z. Djurdjevic, I. Jancic, B. Bufan, M. Milenkovic, R. Jankovic, V. Miskovic-Stankovic, B. Obradovic, J. Biomater. Appl. 2018, 32, 1197. https://doi. org/10.1177/0885328218759564.

[52] K. Nuutila, J. Grolman, L. Yang, M. Broomhead, S. Lipsitz, A. Onderdonk, D. Mooney, E. Eriksson, Adv. Wound Care 2020, 9, 48. https://doi.org/10.1089/wound.2019.1018.

[53] H. Ying, J. Zhou, M. Wang, D. Su, Q. Ma, G. Lv, J. Chen, Mater. Sci. Eng. C 2019, 101, 487. https://doi.org/10.1016/j. msec.2019.03.093

[54] S. Zhang, J. Hou, Q. Yuan, P. Xin, H. Cheng, Z. Gu, J. Wu, Chem. Eng. $J$. in press 2019, 392, 123775. https://doi.org/10. 1016/j.cej.2019.123775.

[55] Z. Lin, T. Wu, W. Wang, B. Li, M. Wang, L. Chen, H. Xia, T. Zhang, Int. J. Biol. Macromol. 2019, 140, 330. https://doi. org/10.1016/j.ijbiomac.2019.08.087.

[56] W. Li, F. Gao, J. Kan, J. Deng, B. Wang, S. Hao, Colloid. Surface. B 2019, 175, 436. https://doi.org/10.1016/j.colsurfb.2018. 12.020 .

[57] P. Chuysinuan, N. Chimnoi, N. Reuk-Ngam, P. Khlaychan, A. Makarasen, N. Wetprasit, D. Dechtrirat, P. Supaphol, S. Techasakul, Polym. Bull. 2019, 76, 701. https://doi.org/10. 1007/s00289-018-2395-x.

[58] Y. Du, L. Li, H. Peng, H. Zheng, S. Cao, G. Lv, A. Yang, H. Li, T. Liu, Macromol. Biosci. 2019, 20, 1900303. https://doi. org/10.1002/mabi.201900303.

[59] M. Gholipourmalekabadi, S. Sapru, A. Samadikuchaksaraei, R. L. Reis, D. L. Kaplan, S. C. Kundu, Adv. Drug Deliv. Rev. in press 2019, 1. https://doi.org/10.1016/j.addr.2019.09.003.

[60] M. Salehi-Abari, N. Koupaei, S. A. Hassanzadeh-Tabrizi, Mater. Technol. 2019, 2019, 1. https://doi.org/10.1080/ 10667857.2019.1678088.

[61] E. Fages, J. Pascual, O. Fenollar, D. Garcia-Sanoguera, R. Balart, Polym. Eng. Sci. 2011, 51, 804. https://doi.org/10. 1002/pen21889.

[62] P. Pankongadisak, S. Sangklin, P. Chuysinuan, O. Suwantong, P. Supaphol, J. Drug Deliv. Sci. Technol. 2019, 53, 101121. https://doi.org/10.1016/j.jddst.2019.06.018.

[63] P. Ghaffari-Bohlouli, F. Hamidzadeh, P. Zahedi, M. Shahrousvand, M. Fallah-Darrehchi, J. Biomater. Sci. Polym. Ed. 2019, 31, 219. https://doi.org/10.1080/09205063.2019.1683265.

[64] H. Maleki, S. Mathur, Polym. Eng. Sci. in press 2020, 1. https://doi.org/10.1002/pen.25375.

[65] M. S. Kim, G. W. Oh, Y. M. Jang, S. C. Ko, W. S. Park, I. W. Choi, Y. M. Kim, W. K. Jung, Mater. Sci. Eng. C 2020, 107, 110352. https://doi.org/10.1016/j.msec.2019.110352.

[66] R. Alipour, A. Khorshidi, A. F. Shojaei, F. Mashayekhi, M. J. M. Moghaddam, Polym. Test. 2019, 79, 106022. https:// doi.org/10.1016/j.polymertesting.2019.106022.

[67] R. Augustine, A. Hasan, V. K. Yadu Nath, J. Thomas, A. Augustine, N. Kalarikkal, A. E. Al Moustafa, S. Thomas, J. Mater. Sci. Mater. Med. 2018, 29, 163. https://doi.org/10. 1007/s10856-018-6169-7.

[68] S. K. Bajpai, N. Chand, M. Mahendra, Polym. Eng. Sci. 2013, 53, 1751. https://doi.org/10.1002/pen23424.

[69] J. Zhu, F. Li, X. Wang, J. Yu, D. Wu, ACS Appl. Mater. Inter. 2018, 10, 13304. https://doi.org/10.1021/acsami.7b18927.

[70] F. Croisier, C. Jerome, Eur. Polym. J. 2013, 49, 780. https:// doi.org/10.1016/j.eurpolymj.2012.12.009. 
[71] H. Hamedi, S. Moradi, S. M. Hudson, A. E. Tonelli, Carbohydr. Polym. 2018, 199, 445. https://doi.org/10.1016/j. carbpol.2018.06.114.

[72] S. Sur, A. Rathore, V. Dave, K. R. Reddy, R. S. Chouhan, V. Sadhu, Nano-Struct. Nano-Objects 2019, 20, 100397. https://doi.org/10.1016/j.nanoso.2019.100397.

[73] K. I. Matshetshe, S. Parani, S. M. Manki, O. S. Oluwafemi, Int. J. Biol. Macromol. 2018, 118, 676. https://doi.org/10.1016/ j.ijbiomac.2018.06.125.

[74] M. Kong, X. G. Chen, K. Xing, H. J. Park, Int. J. Food Microbiol. 2010, 144, 51. https://doi.org/10.1016/j. ijfoodmicro.2010.09.012.

[75] W. Paul, C. Sharma, Trends Biomater. Artif. Organs 2004, 18, $18 \mathrm{http}: / /$ medind.nic.in/taa/t04/i1/taat04i1p18.pdf.

[76] H. Liu, Y. Du, X. Wang, L. Sun, Int. J. Food Microbiol. 2004, 95, 147. https://doi.org/10.1016/j.ijfoodmicro.2004.01.022.

[77] L. Y. Zheng, J. F. Zhu, Carbohydr. Polym. 2003, 54, 527. https://doi.org/10.1016/j.carbpol.2003.07.009.

[78] X. F. Liu, Y. L. Guan, D. Z. Yang, Z. Li, K. D. Yao, J. Appl. Polym. Sci 2001, 79, 1324. https://doi.org/10.1002/1097-4628 (20010214)79:7<1324::AID-APP210>3.0.CO;2-L.

[79] Y. Chung, Y. Su, C. Chen, G. Jia, H. Wang, J. C. G. Wu, J. Lin, Acta Pharmacol. Sin. 2004, 25, 932.

[80] H. Ueno, T. Mori, T. Fujinaga, Adv. Drug Deliv. Rev. 2001, 52, 105. https://doi.org/10.1016/S0169-409X(01)00189-2.

[81] S. Agnihotri, S. Mukherji, S. Mukherji, Appl. Nanosci. 2012, 2, 179. https://doi.org/10.1007/s13204-012-0080-1.

[82] H. V. Tran, L. D. Tran, C. T. Ba, H. D. Vu, T. N. Nguyen, D. G. Pham, P. X. Nguyen, Colloid. Surf. A 2010, 360, 32. https://doi.org/10.1016/j.colsurfa.2010.02.007.

[83] A. M. Abdelgawad, S. M. Hudson, O. J. Rojas, Carbohydr. Polym. 2014, 100, 166. https://doi.org/10.1016/j.carbpol.2012. 12.043 .

[84] M. Kozicki, M. Kołodziejczyk, M. Szynkowska, A. Pawlaczyk, E. Lesćniewska, A. Matusiak, A. Adamus, A. Karolczak, Carbohydr. Polym. 2016, 140, 74. https://doi.org/10.1016/j. carbpol.2015.12.017.

[85] J. Venkatesan, J.-Y. Lee, D. S. Kang, S. Anil, S.-K. Kim, M. S. Shim, D. G. Kim, Int. J. Biol. Macromol. 2017, 98, 515. https://doi.org/10.1016/j.ijbiomac.2017.01.120.

[86] W. Mozalewska, R. Czechowska-Biskup, A. K. Olejnik, R. A. Wach, P. Ulański, J. M. Rosiak, Radiat. Phys. Chem. 2017, 134, 1. https://doi.org/10.1016/j.radphyschem.2017.01.003.

[87] B. Tyliszczak, A. Drabczyk, S. Kudłacik-Kramarczyk, K. Bialik-Wąs, R. Kijkowska, A. Sobczak-Kupiec, Colloid. Surf. B 2017, 160, 325. https://doi.org/10.1016/j.colsurfb.2017. 09.044 .

[88] N. T. P. Nguyen, L. V. H. Nguyen, N. T. Thanh, V. Van Toi, T. Ngoc Quyen, P. A. Tran, H. M. David Wang, T. H. Nguyen, Mater. Lett. 2019, 248, 241. https://doi.org/10. 1016/j.matlet.2019.03.103.

[89] S. R. Ur Rehman, R. Augustine, A. A. Zahid, R. Ahmed, M. Tariq, A. Hasan, Int. J. Nanomed. 2019, 14, 9603. https:// doi.org/10.2147/IJN.S218120.

[90] G. Shi, W. Chen, Y. Zhang, X. Dai, X. Zhang, Z. Wu, Langmuir 2019, 35, 1837. https://doi.org/10.1021/acs.langmuir. 8 b01834.

[91] T. Khampieng, S. Wongkittithavorn, S. Chaiarwut, P. Ekabutr, P. Pavasant, P. Supaphol, J. Drug Deliv. Sci.
Technol. 2018, 44, 91. https://doi.org/10.1016/j.jddst.2017. 12.005 .

[92] L. F. G. Chabala, C. E. E. Cuartas, M. E. L. O. López, Mar. Drugs 2017, 15, 328. https://doi.org/10.3390/md15100328.

[93] B. Lu, F. Lu, Y. Zou, J. Liu, B. Rong, Z. Li, F. Dai, D. Wu, G. Lan, Carbohydr. Polym. 2017, 173, 556. https://doi.org/10. 1016/j.carbpol.2017.06.035.

[94] H. Ferfera-Harrar, D. Berdous, T. Benhalima, Polym. Bull. 2018, 75, 2819. https://doi.org/10.1007/s00289-017-2183-z.

[95] I. Gholamali, M. Asnaashariisfahani, E. Alipour, Regen. Eng. Transl. Med. 2019, 2019, 1. https://doi.org/10.1007/s40883019-00120-7.

[96] N. T. Hiep, H. C. Khon, V. V. T. Niem, V. Van Toi, T. N. Quyen, N. D. Hai, M. Ngoc, T. Anh, Int. J. Polym. Sci. 2016, 2016, 1. https://doi.org/10.1155/2016/1584046.

[97] Y. Xie, X. Liao, J. Zhang, F. Yang, Z. Fan, Int. J. Biol. Macromol. 2018, 119, 402. https://doi.org/10.1016/j.ijbiomac. 2018.07.060.

[98] M. Pérez-Díaz, E. Alvarado-Gomez, M. Magaña-Aquino, R. Sánchez-Sánchez, C. Velasquillo, C. Gonzalez, A. GanemRondero, G. Martínez-Castañon, N. Zavala-Alonso, F. Martinez-Gutierrez, Mater. Sci. Eng. C 2016, 60, 317. https://doi.org/10.1016/j.msec.2015.11.036.

[99] A. I. Mekkawy, M. A. El-Mokhtar, N. A. Nafady, N. Yousef, M. Hamad, S. M. El-Shanawany, E. H. Ibrahim, M. Elsabahy, Int. J. Nanomedicine 2017, 12, 759. https://doi.org/10.2147/ IJN.S124294.

[100] C. H. Yang, L. S. Wang, S. Y. Chen, M. C. Huang, Y. H. Li, Y. C. Lin, P. F. Chen, J. F. Shaw, K. S. Huang, Int. J. Pharm. 2016, 510, 493. https://doi.org/10.1016/j.ijpharm.2016.01.010.

[101] A. K. d. S. Pereira, D. T. Reis, K. M. Barbosa, G. N. Scheidt, L. S. da Costa, L. S. S. Santos, Carbohydr. Res 2020, 488, 107891. https://doi.org/10.1016/j.carres.2019.107891.

[102] R. Choudhury, M. Majumdar, P. Biswas, S. Khan, T. K. Misra, Nano-Struct. Nano-Objects 2019, 19, 100326. https://doi.org/10.1016/j.nanoso.2019.100326.

[103] F. Mohanty, S. K. Swain, Nano-Struct. Nano-Objects 2019, 18, 100300. https://doi.org/10.1016/j.nanoso.2019.100300.

[104] J. M. A. Escobar-Hernández, J. C. M. Escobar-Remolina, Nano-Struct. Nano-Objects 2019, 17, 259. https://doi.org/10. 1016/j.nanoso.2019.01.005.

[105] G. Chitra, D. S. Franklin, S. Sudarsan, M. Sakthivel, S. Guhanathan, Polym. Eng. Sci. 2018, 58, 2133. https://doi. org/10.1002/pen.24824.

[106] O. S. Oluwafemi, J. L. Anyik, N. E. Zikalala, E. H. M. Sakho, Nano-Struct. Nano-Objects 2019, 20, 100387. https://doi.org/ 10.1016/j.nanoso.2019.100387.

[107] O. T. Jemilugba, E. H. M. Sakho, S. Parani, V. Mavumengwana, O. S. Oluwafemi, Colloids Interface Sci. Commun. 2019, 31, 100191. https://doi.org/10.1016/j.colcom.2019.100191.

[108] T. T. Vo, T. T. N. Nguyen, T. T. T. Huynh, T. T. T. Vo, T. T. N. Nguyen, D. T. Nguyen, V. S. Dang, C. H. Dang, T. D. Nguyen, J. Nanomater. 2019, 2019, 8385935. https://doi. org/10.1155/2019/8385935.

[109] L. Ran, Y. Zou, J. Cheng, F. Lu, Int. J. Biol. Macromol. 2019, 125, 392. https://doi.org/10.1016/j.ijbiomac.2018.12.052.

[110] N. Masood, R. Ahmed, M. Tariq, Z. Ahmed, M. S. Masoud, I. Ali, R. Asghar, A. Andleeb, A. Hasan, Int. J. Pharm. 2019, 559, 23. https://doi.org/10.1016/j.ijpharm.2019.01.019. 
[111] J. Verma, J. Kanoujia, P. Parashar, C. B. Tripathi, S. A. Saraf, Drug Deliv. Transl. Res. 2017, 7, 77. https://doi.org/10.1007/ s13346-016-0322-y.

[112] C. Ryan, E. Alcock, F. Buttimer, M. Schmidt, D. Clarke, M. Pemble, M. Bardosova, Sci. Technol. Adv. Mater. 2017, 18, 528. https://doi.org/10.1080/14686996.2017.1344929.

[113] F. Wahid, H. S. Wang, C. Zhong, L. Q. Chu, Carbohydr. Polym. 2017, 165, 455. https://doi.org/10.1016/j.carbpol.2017.02.085.

[114] J. Maitra, V. K. Shukla, Am. J. Polym. Sci. 2014, 4, 25. https:// doi.org/10.5923/j.ajps.20140402.01.

[115] B. Hoffmann, D. Seitz, A. Mencke, A. Kokott, G. Ziegler, J. Mater. Sci. Mater. Med. 2009, 20, 1495. https://doi.org/10. 1007/s10856-009-3707-3.

[116] S. Duygu Sütekin, O. Güven, Appl. Radiat. Isot. 2019, 145, 161. https://doi.org/10.1016/j.apradiso.2018.12.028.

[117] T. Fukumori, T. Nakaoki, J. Appl. Polym. Sci. 2014, 131, 1. https://doi.org/10.1002/app.40578.

[118] C. M. Hassan, N. A. Peppas, Adv. Polym. Sci. 2000, 153, 37. https://doi.org/10.1007/3-540-46414-X_2.

[119] N. A. Peppas, S. R. Stauffer, J. Control. Release 1991, 16, 305. https://doi.org/10.1016/0168-3659(91)90007-Z.

[120] B. Obradovic, J. Stojkovska, Z. Jovanovic, V. MiskovicStankovic, J. Mater. Sci. Mater. Med. 2012, 23, 99. https://doi org/10.1007/s10856-011-4522-1.

[121] M. D. Figueroa-Pizano, I. Vélaz, F. J. Peñas, P. Zavala-Rivera, A. J. Rosas-Durazo, A. D. Maldonado-Arce, M. E. MartínezBarbosa, Carbohydr. Polym. 2018, 195, 476. https://doi.org/10. 1016/j.carbpol.2018.05.004.

[122] R. Surudžić, A. Janković, M. Mitrić, I. Matić, Z. D. Juranić, L. Živković, V. Mišković-Stanković, K. Y. Rhee, S. J. Park, D. Hui, J. Ind. Eng. Chem. 2016, 34, 250. https://doi.org/10. 1016/j.jiec.2015.11.016.

[123] D. Wei, W. Sun, W. Qian, Y. Ye, X. Ma, Carbohydr. Res. 2009, 344, 2375. https://doi.org/10.1016/j.carres.2009.09.001.

[124] G. Lawrie, I. Keen, B. Drew, A. Chandler-Temple, L. Rintoul, P. Fredericks, L. Grøndahl, Biomacromolecules 2007, 8, 2533. https://doi.org/10.1021/bm070014y.

[125] J. Stojkovska, J. Zvicer, Ž. Jovanović, V. Mišković-Stanković, B. Obradović, J. Serbian Chem. Soc. 2012, 77, 1709. https:// doi.org/10.2298/JSC121108148S.

[126] B. Obradovic, V. Miskovic-Stankovic, Silver nanoparticles in alginate solutions and hydrogels aimed for biomedical applications. in Silver Nanoparticles: Synthesis, Uses Health Concerns (Eds: I. Armentano, J. M. Kenny), Nova Science Publishers, Hauppauge, New York 2013, p. 247.

[127] K. Nešović, A. Janković, T. Radetić, A. P. Grujić, M. V. Sekulić, V. Kojić, K. Y. Rhee, J. Electrochem. Sci. Eng. 2020, 10, 185. https://doi.org/10.5599/jese.732.

[128] V. Mišković-Stanković, Electrochemical Production of Polymer Hydrogels with Silver Nanoparticles for Medical Applications as Wound Dressings and Soft Tissue Implants. in Biomedical Pharmaceutical Applications of Electrochemistry (Ed: S. Djokic), Springer International Publishing, Switzerland 2016, p. 267. https://doi.org/10.1007/978-3-319-31849-3.

[129] G. Merga, R. Wilson, G. Lynn, B. H. Milosavljevic, D. Meisel, J. Phys. Chem. C 2007, 111, 12220. https://doi.org/10.1021/ jp074257w.

[130] Z. Jovanovic, A. Radosavljevic, J. Stojkovska, B. Nikolic, B. Obradovic, Z. Kacarevic-Popovic, V. Miskovic-Stankovic,
Polym. Compos. 2014, 35, 217. https://doi.org/10.1002/pc. 22653.

[131] Z. Jovanovic, A. Radosavljevic, Z. Kacarevic-Popovic, V. Miskovic-Stankovic, Hem. Ind. 2011, 65, 687. https://doi. org/10.2298/hemind110915064j.

[132] A. Slistan-Grijalva, R. Herrera-Urbina, J. F. Rivas-Silva, M. Avalos-Borja, F. F. Castillon-Barraza, A. PosadaAmarillas, Syst. Nanostruct. 2005, 27, 104. https://doi.org/10. 1016/j.physe.2004.10.014.

[133] X. Cai, M. Lin, S. Tan, W. Mai, Y. Zhang, Z. Liang, Z. Lin, X. Zhang, Carbon 2012, 50, 3407. https://doi.org/10.1016/j. carbon.2012.02.002.

[134] J. Ma, J. Zhang, Z. Xiong, Y. Yong, X. S. Zhao, J. Mater. Chem. 2011, 21, 3350. https://doi.org/10.1039/c0jm02806a.

[135] A. C. M. de Moraes, B. A. Lima, A. F. de Faria, M. Brocchi, O. L. Alves, Int. J. Nanomed. 2015, 10, 6847. https://doi.org/ 10.2147/IJN.S90660.

[136] G. A. Martinez-Castanon, N. Niño-Martínez, F. MartínezGutierrez, J. R. Martínez-Mendoza, F. Ruiz, J. Nanoparticle Res. 2008, 10, 1343. https://doi.org/10.1007/s11051-0089428-6.

[137] C. Liao, Y. Li, S. C. Tjong, Int. J. Mol. Sci. 2019, 20, 1. https:// doi.org/10.3390/ijms20020449.

[138] T. Dutta, N. N. Ghosh, A. P. Chattopadhyay, M. Das, NanoStruct. Nano-Objects 2019, 20, 100393. https://doi.org/10. 1016/j.nanoso.2019.100393.

[139] Y. Murali Mohan, K. Lee, T. Premkumar, K. E. Geckeler, Polymer. 2007, 48, 158. https://doi.org/10.1016/j.polymer. 2006.10.045.

[140] J. Zvicer, V. Miskovic-Stankovic, B. Obradovic, J. Biomed, Mater. Res. - Part A 2019, 107, 755. https://doi.org/10.1002/ jbm.a.36590.

[141] F. Sun, H. R. Nordli, B. Pukstad, E. Kristofer Gamstedt, G. Chinga-Carrasco, J. Mech. Behav. Biomed. Mater. 2017, 69, 377. https://doi.org/10.1016/j.jmbbm.2017.01.049.

[142] P. G. Agache, C. Monneur, J. L. Leveque, J. De Rigal, Arch. Dermatol. Res. 1980, 269, 221. https://doi.org/10.1007/ BF00406415.

[143] J. Stojkovska, B. Bugarski, B. Obradovic, J. Mater. Sci. Mater. Med. 2010, 21, 2869. https://doi.org/10.1007/s10856-010-4135-0.

[144] J. Krstić, J. Spasojević, A. Radosavljević, A. Perić-Grujić, M. Đurić, Z. Kačarević-Popović, S. Popović, J. Appl. Polym. Sci. 2014, 2014, 40321. https://doi.org/10.1002/app.40321.

[145] P. L. Ritger, N. A. Peppas, J. Control. Release 1987, 5(23), 23. https://doi.org/10.1016/0168-3659(87)90034-4.

[146] M. P. Mullarney, T. A. P. Seery, R. A. Weiss, Polymer. 2006, 47, 3845. https://doi.org/10.1016/j.polymer.2006.03.096.

[147] J. Spasojević, A. Radosavljević, J. Krstić, D. Jovanović, V. Spasojević, M. Kalagasidis-Krušić, Z. Kačarević-Popović, Eur. Polym. J. 2015, 69, 168. https://doi.org/10.1016/j. eurpolymj.2015.06.008.

[148] M. R. Reithofer, A. Lakshmanan, A. T. K. Ping, J. M. Chin, C. A. E. Hauser, Biomaterials 2014, 35, 7535. https://doi.org/ 10.1016/j.biomaterials.2014.04.102.

[149] K. Jamuna-Thevi, S. A. Bakar, S. Ibrahim, N. Shahab, M. R. M. Toff, Vacuum 2011, 86, 235. https://doi.org/10.1016/ j.vacuum.2011.06.011.

[150] P. L. Ritger, N. A. Peppas, J. Control. Release 1987, 5(37), 37. https://doi.org/10.1016/0168-3659(87)90035-6. 
[151] R. W. Korsmeyer, R. Gurny, E. Doelker, P. Buri, N. A. Peppas, Int. J. Pharm 1983, 15(25), 25. https://doi.org/ 10.1016/0378-5173(83)90064-9.

[152] M. Kopcha, N. G. Lordi, K. J. Tojo, J. Pharm. Pharmacol. 1991, 43, 382. https://doi.org/10.1111/j.2042-7158.1991. tb03493.x.

[153] J. Pais, J. Online Math. Its Appl. 2001, 1, 1 https://www.maa. org/press/periodicals/loci/joma/intuiting-mathematicalobjects-using-kinetigrams

[154] K. Ghosal, A. Das, S. K. Das, S. Mahmood, M. A. M. Ramadan, S. Thomas, Int. J. Biol. Macromol. 2019, 130, 645. https://doi.org/10.1016/j.ijbiomac.2019.02.117.

[155] J. Helmlinger, C. Sengstock, C. Groß-Heitfeld, C. Mayer, T. A. Schildhauer, M. Köller, M. Epple, RSC Adv. 2016, 6, 18490. https://doi.org/10.1039/c5ra27836h.

[156] Y. Murali Mohan, K. Vimala, V. Thomas, K. Varaprasad, B. Sreedhar, S. K. Bajpai, K. Mohana Raju, J. Colloid Interface Sci. 2010, 342, 73. https://doi.org/10.1016/j.jcis.2009. 10.008 .

[157] N. Alissawi, V. Zaporojtchenko, T. Strunskus, T. Hrkac, I. Kocabas, B. Erkartal, V. S. K. Chakravadhanula, L. Kienle, G. Grundmeier, D. Garbe-Schönberg, F. Faupel, J. Nanoparticle Res. 2012, 14, 928. https://doi.org/10.1007/ s11051-012-0928-z.

[158] V. Pareek, R. Gupta, J. Panwar, Mater. Sci. Eng. C 2018, 90, 739. https://doi.org/10.1016/j.msec.2018.04.093.

[159] T. Taylor, C. Unakal. Staphylococcus aureus. StatPearls [Internet]. Treasure Isl. StatPearls Publ. 2019 Jan-. Available from https//Www.Ncbi.Nlm.Nih.Gov/Books/NBK441868/ (2019).

[160] A. Sirelkhatim, S. Mahmud, A. Seeni, N. H. M. Kaus, L. C. Ann, S. K. M. Bakhori, H. Hasan, D. Mohamad, NanoMicro Lett. 2015, 7, 219. https://doi.org/10.1007/s40820-0150040-x.

[161] V. Lakshmi Prasanna, R. Vijayaraghavan, Langmuir 2015, 31, 9155. https://doi.org/10.1021/acs.langmuir.5b02266.

[162] H. Xu, F. Qu, H. Xu, W. Lai, Y. A. Wang, Z. P. Aguilar, H. Wei, BioMetals 2012, 25, 45. https://doi.org/10.1007/ s10534-011-9482-x.

[163] M. D. Scherer, J. C. V. Sposito, W. F. Falco, A. B. Grisolia, L. H. C. Andrade, S. M. Lima, G. Machado, V. A. Nascimento,
D. A. Gonçalves, H. Wender, S. L. Oliveira, A. R. L. Caires, Sci. Total Environ. 2019, 660, 459. https://doi.org/10.1016/j. scitotenv.2018.12.444.

[164] E. M. Luther, Y. Koehler, J. Diendorf, M. Epple, R. Dringen, Nanotechnol. 2011, 22, 1. https://doi.org/10.1088/0957-4484/ 22/37/375101.

[165] C. Carlson, S. M. Hussein, A. M. Schrand, L. K. BraydichStolle, K. L. Hess, R. L. Jones, J. J. Schlager, J. Phys. Chem. B 2008, 112, 13608. https://doi.org/10.1021/jp712087m.

[166] A. R. Gliga, S. Skoglund, I. Odnevall Wallinder, B. Fadeel, H. L. Karlsson, Part. Fibre Toxicol 2014, 11(1), 11. https://doi. org/10.1186/1743-8977-11-11.

[167] A. Ivask, I. Kurvet, K. Kasemets, I. Blinova, V. Aruoja, S. Suppi, H. Vija, A. Kakćinen, T. Titma, M. Heinlaan, M. Visnapuu, D. Koller, V. Kisand, A. Kahru, PLoS One 2014, 9, e102108. https://doi.org/10.1371/journal.pone.0102108.

[168] T. H. Kim, M. Kim, H. S. Park, U. S. Shin, M. S. Gong, H. W. Kim, J. Biomed, Mater. Res. - Part A 2012, 100A, 1033. https://doi.org/10.1002/jbm.a.34053.

[169] S. George, S. Lin, Z. Ji, C. R. Thomas, L. Li, M. Mecklenburg, H. Meng, X. Wang, H. Zhang, T. Xia, J. N. Hohman, S. Lin, J. I. Zink, P. S. Weiss, A. E. Nel, ACS Nano 2012, 6, 3745. https://doi.org/10.1021/nn204671v.

[170] T. L. Riss, R. A. Moravec, A. L. Niles, S. Duellman, H. A. Benink, T. J. Worzella, et al. Eds., Cell Viability Assays, Eli Lilly \& Company and the National Center for Advancing Translational Sciences, Bethesda (MD) 2004, p. 1 http:// www.ncbi.nlm.nih.gov/pubmed/23805433.

[171] J. Y. Je, Y. S. Cho, S. K. Kim, Bioorganic Med. Chem. Lett. 2006, 16, 2122. https://doi.org/10.1016/j.bmcl.2006.01.060.

How to cite this article: Nešović $\mathrm{K}$, MiškovićStanković V. A comprehensive review of the polymer-based hydrogels with electrochemically synthesized silver nanoparticles for wound dressing applications. Polym Eng Sci. 2020;60: 1393-1419. https://doi.org/10.1002/pen.25410 